\title{
Astronomical calibration of the Toarcian Stage: implications for sequence stratigraphy and duration of the early Toarcian OAE
}

\author{
Slah Boulila ${ }^{a, b,{ }^{*}}$, Bruno Galbrun ${ }^{a}$, Emilia Huret ${ }^{c}$, Linda A. Hinnov ${ }^{d}$, \\ Isabelle Rouget ${ }^{e}$, Silvia Gardin ${ }^{e}$, and Annachiara Bartolini ${ }^{\dagger}$ \\ a Université Paris VI, CNRS - UMR 7193 ISTeP 'Institut des Sciences de la Terre-Paris', case 117, 4, place Jussieu, 75252 \\ Paris cedex 05, France \\ ${ }^{\mathrm{b}}$ ASD, IMCCE-CNRS UMR8028, Observatoire de Paris, UPMC, 77 avenue Denfert-Rochereau, 75014 Paris, France \\ ${ }^{c}$ ANDRA DS/ Milieu Géologique, 1/7, rue Jean Monnet, F-92290 Châtenay-Malabry Cedex, France \\ ${ }^{\mathrm{d}}$ Morton K. Blaustein Department of Earth and Planetary Sciences, Johns Hopkins University, 3400 North Charles Street, \\ Baltimore, Maryland 21218, USA \\ ${ }^{\text {e }}$ CNRS - UMR 7207 CR2P, Université Paris VI, case 104, 4 place Jussieu, 75252 Paris cedex, France \\ ${ }^{f}$ CNRS - UMR 7207 CR2P, MNHN, 8, rue Buffon, 75005 Paris, France \\ * Corresponding author. slah.boulila@upmc.fr (S. Boulila
}

\begin{abstract}
The Toarcian Oceanic Anoxic Event (T-OAE) of the early Jurassic period involves one of the largest perturbations of the carbon cycle in the past $250 \mathrm{Ma}$, recorded by a pronounced negative carbon-isotope excursion (CIE). Numerous studies have focused on potential causes of the T-OAE and CIE, but are hampered by an uncertain timescale. Here we present high-resolution ( 2 kyr) magnetic susceptibility (MS) measurements from the marine marls of the Sancerre-Couy drill-core, southern Paris Basin, spanning the entire Toarcian Stage. The MS variations document a rich series of sub-Milankovitch to Milankovitch frequencies (precession, obliquity and eccentricity) with the periodic $g_{2}-g_{5}$ (405 kyr) and quasi-periodic $g_{4}-g_{3}$ ( 2.4 Myr Cenozoic mean periodicity) eccentricity terms being the most prominent. The MS-related $g_{4}-g_{3}$ variation reflects third-order eustatic sequences, and constrains the sequence stratigraphic framework of the Toarcian Stage. In addition, MS variations reveal a modulation of $g_{2}-g_{5}$ by $g_{4}-g_{3}$ eccentricity related cycles, suggesting that sea-level change was the main control on the deposition of the Toarcian Sancerre marls, in tune with the astro-climatic frequencies. The stable $405 \mathrm{kyr}$ cyclicity constrains a minimum duration of the Toarcian Stage to $8.3 \mathrm{Myr}$, and the well documented $\mathrm{CIE}$, associated with the T-OAE, to 300 to $500 \mathrm{kyr}$. The $405 \mathrm{kyr}$ MS timescale calibrates the periodicity of the prominent high-frequency $\delta^{13} \mathrm{C}$ cycles that occur in the decreasing part of the CIE to 30 to $34 \mathrm{kyr}$, consistent with the Toarcian obliquity period predicted for an Earth experiencing sustained tidal dissipation.
\end{abstract}

Keyword: Early Jurassic, orbital forcing, $g_{2}-g_{5}$ and $g_{4}-g_{3}$ eccentricity terms, eustatic sequences, $405 \mathrm{kyr}$ eccentricity tuning, Toarcian timescale, CIE duration.

\section{Introduction}

The Early Jurassic Toarcian age is a pivotal time in the Mesozoic era, marked in its earliest part by a severe global warming of the Earth's surface systems and by widespread oceanic anoxia (the Toarcian Oceanic Anoxic Event, T-OAE) (e.g., Hesselbo et al., 2000, 2007; Bailey et al., 2003; Kemp et al., 2005; McElwain et al., 2005; Wignall et al., 2005; Cohen et al., 2007; Mattioli et al., 2008; McArthur et al., 2008; Dera et al., 2009; Hermoso et al., 2009a,b, 2012). Assessment of the duration of the T-OAE is of paramount importance in order to understand rates of the associated geological processes, and to decipher causal mechanisms of the event. Numerous geochemical and paleontological studies have been undertaken to better understand the T-OAE, but only a few have attempted to estimate its duration 
(Kemp et al., 2005, 2011; Suan et al., 2008). These estimates were based on astronomical cycle counting, for which the periodicities are poorly constrained for the Mesozoic (e.g., Laskar et al., 2004). Thus, the duration of the carbon isotope excursion (CIE) associated with the T-OAE remains under debate.

Moreover, the Toarcian timescale is poorly constrained (Pálfy et al., 2000; Hinnov and Ogg, 2007). Despite cyclostratigraphic studies that have been performed to time-calibrate Lower Toarcian sequences and the associated T-OAE, none has covered the entire Toarcian Stage. An astronomical calibration of the Toarcian Stage is extremely desirable to not only estimate the duration of T-OAE, but also to better understand the primary driver of depositional sequences within this relatively long Jurassic Stage (Gradstein et al., 2004, 2012). In particular, astronomical tuning of the Toarcian Stage will provide important constraints on durations of the associated sea-level sequences (Hardenbol et al., 1998).

In this study we analyze high-resolution magnetic susceptibility (MS) data from the Paris Basin encompassing the entire Toarcian Stage. Our goal is to calibrate the durations of the Toarcian Stage, substages, and ammonite zones, using $405 \mathrm{kyr}$ orbital eccentricity cycles inferred from the data. Based on a previous characterization of the T-OAE CIE in the Paris Basin (Hermoso et al., 2009a), we used the generated astronomical timescale to estimate the duration of the CIE. Our results indicate a $\sim 8.3 \mathrm{Myr}$ minimum duration of the Toarcian Stage, close to that assigned in previous work (Hinnov and Park, 1999; Gradstein et al., 2004). However, durations of the Middle and Upper Toarcian substages and of most of the ammonite zones are significantly different from previous studies. The CIE duration is estimated as 300 to $500 \mathrm{kyr}$, similar to that inferred from Yorkshire (England) sequences (Kemp et al., 2011), but different from that inferred from Peniche (Portugal) and Dotternhausen (Germany) sequences (Suan et al., 2008). Finally, long-term MS cycles related to long-period eccentricity match the third-order eustatic sequences suggesting that orbitally controlled sea-level was the primary driver of the marls' deposition in the Paris Basin.

\section{Stratigraphic framework of the Toarcian Sancerre core}

The Sancerre-Couy drill-core (Paris Basin) is situated $248 \mathrm{~km}$ south of Paris, in central France (Cher, France, Fig. 1). It is an ultra-deep drill-core encompassing Carboniferous to Middle Jurassic strata. It was drilled in 1986-1987 with the aim to study the magnetic anomaly of the Paris Basin (GPF program 'Géologie Profonde de la France', Lorenz et al., 1987). The Toarcian Stage in the SancerreCouy core is 158-m thick, spanning $\sim 354.3$ to $\sim 196.3 \mathrm{~m}$ depth (Fig. 1). Core lithology is composed of grey marine marls, with a variable carbonate content (Hermoso et al., 2009a) and local benthic macrofauna (Fig. 2). Detrital minerals are represented by clays (illite and chlorite) and quartz (Delavenna et al., 1989). Interpreted 'black shales' are situated between core depths $348.32 \mathrm{~m}$ and $336.9 \mathrm{~m}$ (Lorenz et al., 1991; Hermoso et al., 2009a). The CIE is easily recognized in the core with an amplitude of $~ 6 \%$ 。 in the bulk carbonate $\delta^{13} \mathrm{C}$ (Hermoso et al., 2009a; Fig. 3).

The core provides an excellent recovery of Toarcian ammonite fauna (about 100 specimens) and calcareous nannofossil assemblages. This allowed development of an integrated biostratigraphic framework (Figs. 1 and 2) based on the standard NW Europe ammonite zones (Elmi et al. 1994; Elmi et al. 1997; Howarth 1992) and calcareous nannofossils zones and horizons of the Boreal realm (Bown and Cooper, 1998).

The ammonite biostratigraphy was previously established by Lorenz et al. $(1987,1991)$ and was revised in this study with greater accuracy. Most of Toarcian ammonite zones were recognized; the lower and upper boundaries of the Toarcian Stage can be defined with high precision (Figs. 1 and 2). In spite of their low resolution for this time interval, calcareous nannofossil zones provided additional age control, especially when ammonites were poorly preserved or absent. 


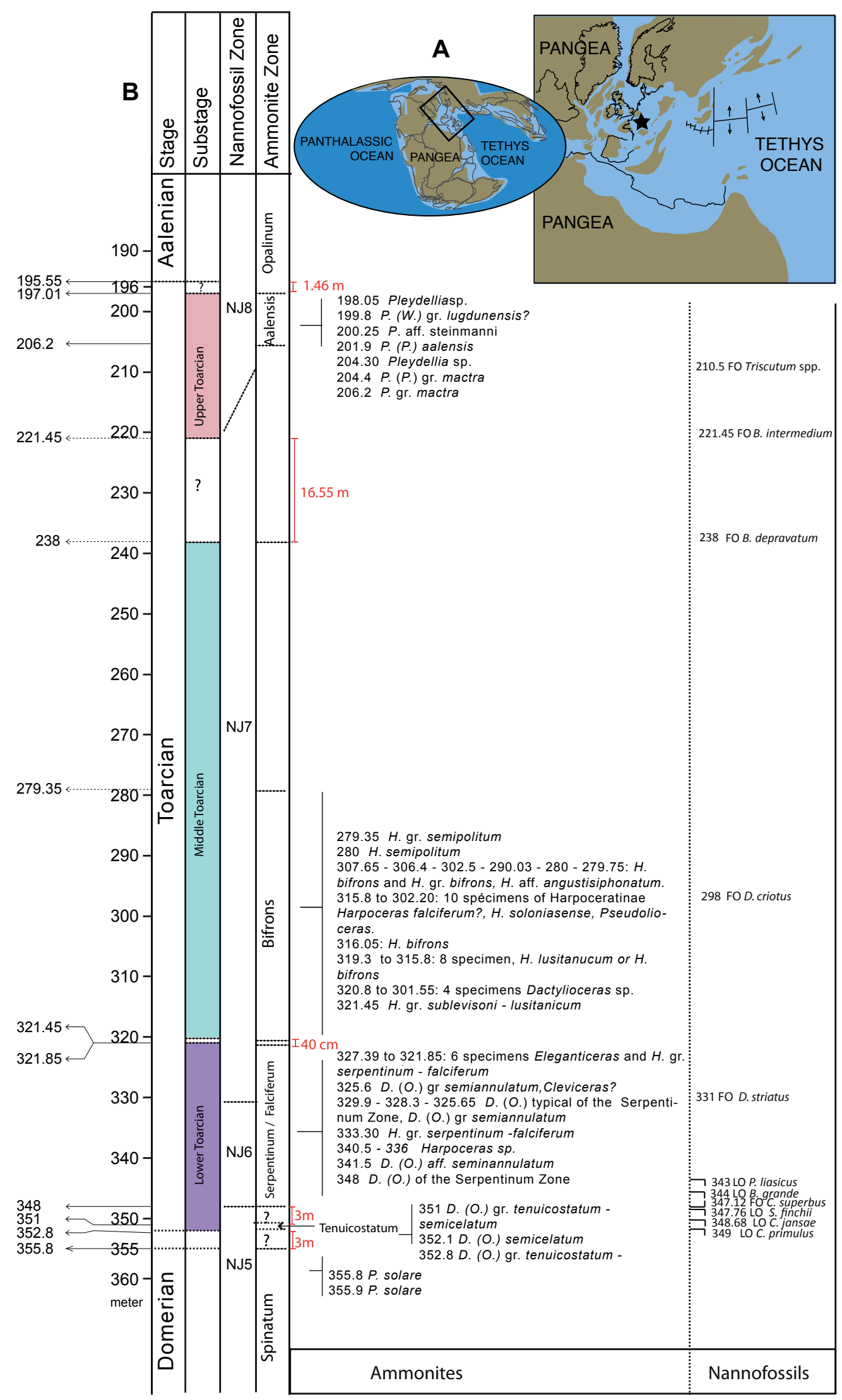

Figure 1: (A) Paleogeographic maps of the Early Jurassic (after Gill et al., 2011). Location of the Sancerre-Couy core (southern Paris Basin, Cher, France) is indicated by a black star. (B) Integrated ammonite-nannofossil biostratigraphic framework of the Sancerre core. All values are positions in meter depth. 
The presence of the ammonite index species Pleuroceras solare at core depth $355.8 \mathrm{~m}$ provides an unequivocal late Pliensbachian age in the $P$. spinatum Zone. The Lower Toarcian is represented by the first occurrence of Dactylioceras (Orthodactylites) tenuicostatum at $352.8 \mathrm{~m}$. The overlying Harpoceras serpentinum Zone is represented from $348 \mathrm{~m}$ to $321.8 \mathrm{~m}$ by the occurrence of typical latest Dactylioceras (Orthodactylites) and by the first appearance of Harpoceratids (Harpoceratoides, Eleganticeras). The succession of calcareous nannofossil horizons from 349 to $331 \mathrm{~m}$ is well calibrated with the base of the Serpentinum Zone (Bown and Cooper, 1998) and thus confirms the age assignment. The middle Toarcian is well recognized at its base with the succession of Hildoceras species $(H$. sublevisoni, $H$. bifrons, $H$. semipolitum) and the occurrence of calcareous nannofossils Discorhabdus striatus and D. criotus (Bown and Cooper, 1998). No ammonite species marker of the Variabilis Zone was found. Although poorly calibrated with the ammonite zones, the occurrence of calcareous nannofossils Biscutum depravatum and B. intermedium (238 $\mathrm{m}$ and $231 \mathrm{~m}$, respectively) could attest to the mid to upper Toarcian (de Kaenel et al., 1996; Bown and Cooper, 1998). Except for the Aalensis Zone, which is well documented by the Pleydellia fauna, the Upper Toarcian ammonite zones are poorly recorded. Calcareous nannofossils provided evidence for a possible late Toarcian (Levesquei Zone; Bown, 1998) through the first occurrences of Triscutum spp from $210 \mathrm{~m}$ and of $T$. sullivani at $202.90 \mathrm{~m}$ (Aalensis Zone; de Kaenel et al., 1996). Detailed ammonite and nannofossil descriptions are provided in the Supplementary file.

\section{Methods}

Magnetic susceptibility (MS) measurements were taken directly on the core, using a Bartington MS2E1 sensor (sensitivity of $2 \times 10^{-6} \mathrm{SI}$ ). The lower part of the Toarcian (360 to $336 \mathrm{~m}$ ) was measured every $2 \mathrm{~cm}$; the remaining interval (336 to $194.55 \mathrm{~m}$ ) was measured every $4 \mathrm{~cm}$. This sampling resulted in 4736 measurements for the Toarcian Stage (Fig. 2).

In order to study the possible origin of the MS signal, hysteresis loops in fields up to $0.8 \mathrm{~T}$ were established for well-spaced samples along the core. All samples show a strong paramagnetic signal caused by clay minerals (Fig. S1). After subtracting this paramagnetic component, there is no clear ferrimagnetic component (Fig. S1). Thus, the MS signal is due to paramagnetic behavior, mainly from clays because of their higher proportions in the marls.

The MS data were linearly interpolated to $2 \mathrm{~cm}$ regular spacing (the MS data are available at http://issues.pangaea.de/browse/PDI-6369). A long-term trend was measured and subtracted (Fig. 2). Following removal of this long-term trend, the data were analyzed using spectral analysis with the multitaper method (MTM, Thomson, 1982) associated with the robust red noise modelling (Mann and Lees, 1996) as implemented in the SSA-MTM Toolkit (Ghil et al., 2002). To extract cycles, we used lowand bandpass filtering using the Taner filter (Taner, 2000). To convert from depth domain to time domain, we time-calibrated the MS record using the $405 \mathrm{kyr}$ eccentricity term, as recommended for Mesozoic stratigraphy by Laskar et al. (2004). In parallel, we performed spectral analysis on Earth's orbital parameters variations for the time interval corresponding to Toarcian time $(175-185 \mathrm{Ma})$ to compare calibrated MS periods with astronomical periods. We also used evolutive FFT analysis to characterize the time-frequency behavior of the investigated time series.

Finally, we performed amplitude modulation (AM) analysis to examine possible AM similarities between the MS and astronomical time series. First, we examined the precession cycle band of the tuned MS series for AM and we compared the retrieved amplitude envelopes with the La2004 orbital eccentricity (Laskar et al., 2004) calculated for Toarcian time. Then, we carried out AM analysis of the eccentricity cycle band again on the tuned MS series. Here we additionally used low pass filtering to extract low-frequency MS cycles related to orbital eccentricity cycles to highlight similarities between low-frequency MS variations and La2004 eccentricity terms. To measure these effects, (1) we band pass filtered the data to isolate precession and short eccentricity and applied the Hilbert transform (e.g. Hinnov, 2000) to extract the AM of the filtered series; and (2) we computed the power spectra of the output AM curves of the precession and short eccentricity to look for significant frequency components that could represent eccentricity terms. 


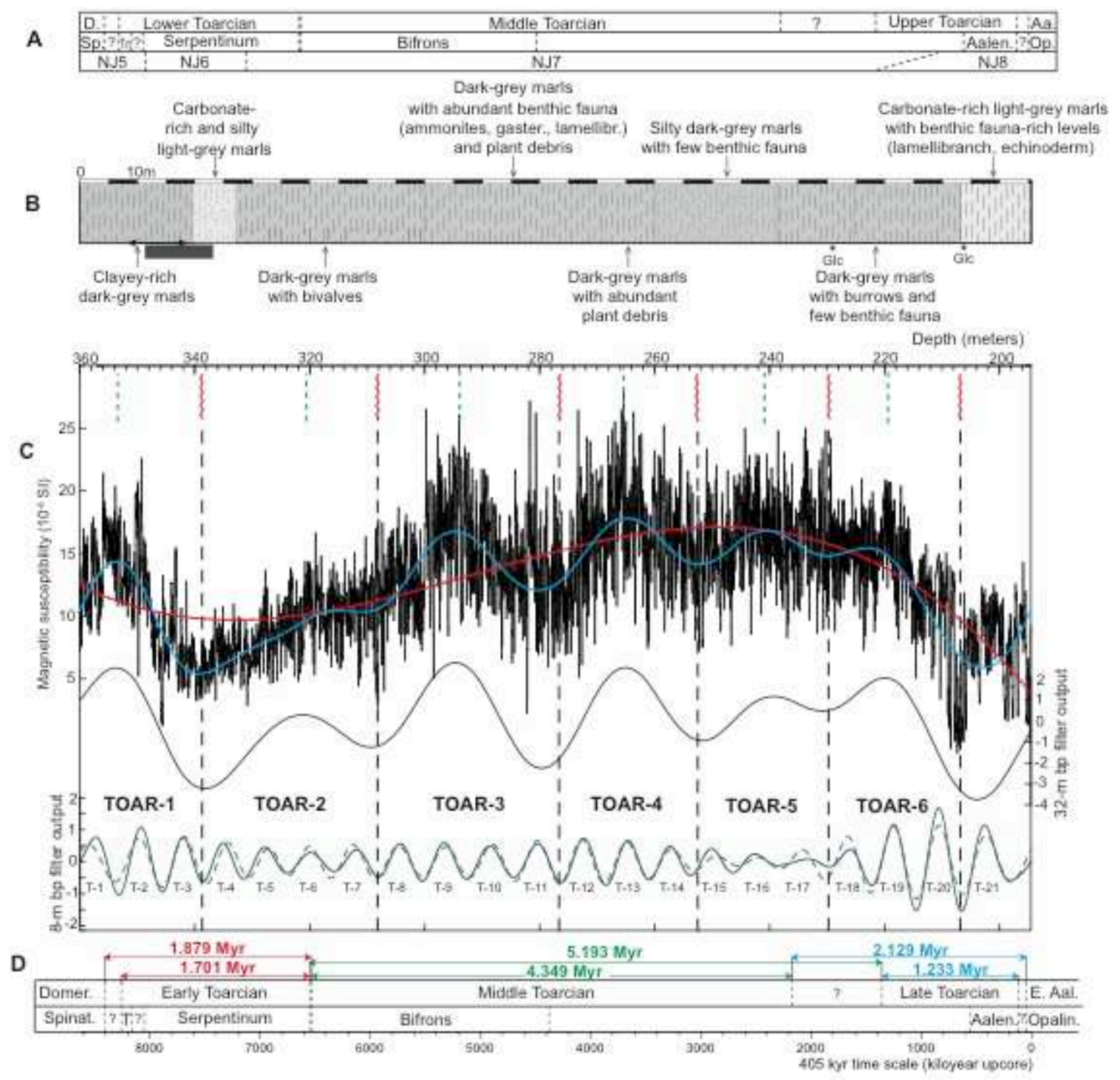

Figure 2: Toarcian Stage integrated stratigraphy of the Sancerre-Couy core (southern Paris Basin, France). (A) Substages (U.P.: Upper Pliensbachian, Aa: Lower Aalenian), ammonite zones (Sp: Spinatum, Tn: Tenuicostatum, Aalen: Aalensis, Op: Opalinum), and nannofossil zones. (B) Sedimentological description: Glc: Glauconite levels; interval of organic-rich marls ('black shales') attributed to the T-OAE event (Hermoso et al., 2009a), are indicated by dark grey rectangles; extent of $\mathrm{CIE}$ is shown by horizontal arrows with the minimum and maximum extents as defined in Fig. 3. (C) Top: Magnetic susceptibility (MS) variations, lowpass filter output (cutoff frequency: 0.06 cycles $/ \mathrm{m}$ ), and a third-order polynomial fit; Middle: bandpass (bp) filter output (cutoff frequencies 0.013 and 0.053 cycles $/ \mathrm{m}$ ) to isolate $32-\mathrm{m}$ cycles (TOAR-1 to TOAR-6); lower curves: bp filter outputs of the MS variations (solid line: cutoff frequencies 0.107 and 0.147 cycles $/ \mathrm{m}$, dashed line: 0.097 and $0.157 \mathrm{cycles} / \mathrm{m}$ ), to isolate $8-\mathrm{m}$ cycles (T1 to 21). Also shown are minima (red vertical wavy lines) and maxima (green vertical dashed lines) of the TOAR cycles, corresponding to sea-level lows and highs in tune with the third-order eustatic sequences (see Section 5.3). (D) Astronomical timescale of the Toarcian Stage and the recognised ammonite zones, assuming that ' $T$ ' cycles correspond to $405 \mathrm{kyr}$ eccentricity cycles.

\section{Results}

\subsection{Spectral analysis}

The MS variations have cyclic patterns across a wide range of frequencies. The lowest frequency components are the most prominent, and characterized by the highest MS amplitudes (Figs. 2 and 4, 
cycles labeled TOAR-1 to 6). The power spectrum of the raw MS series shows two strong peaks of $\sim 8$ and $\sim 32 \mathrm{~m}$, representing the TOAR-1 to TOAR-6, and T-1 to T-21 cycles (Figs. 5 and S2). Numerous other significant peaks with lower power represent higher frequency variations that in part are linked to changes in sedimentation rate. To study these variations in terms of possible astronomical forcing and to reduce effects of variations in sedimentation rate, we computed power spectra per intervals (Fig. 5A,B), and then used $405 \mathrm{kyr}$ eccentricity tuning as follows. Assuming a 7.4 Myr duration of the Toarcian Stage (Hinnov and Park, 1999, see Section 5.1.1), the 8-m thick cyclicity would have a mean period of $\sim 377$ $\mathrm{kyr}$, which is close to the $405 \mathrm{kyr}$ orbital eccentricity cycle period. Calibrating the $8 \mathrm{~m}$ thick cycles (T-1 to $\mathrm{T}-23)$ to a $405 \mathrm{kyr}$ periodicity, results in the alignment of significant frequencies consistent with subMilankovitch and Milankovitch cycles (Fig. 5C,D).

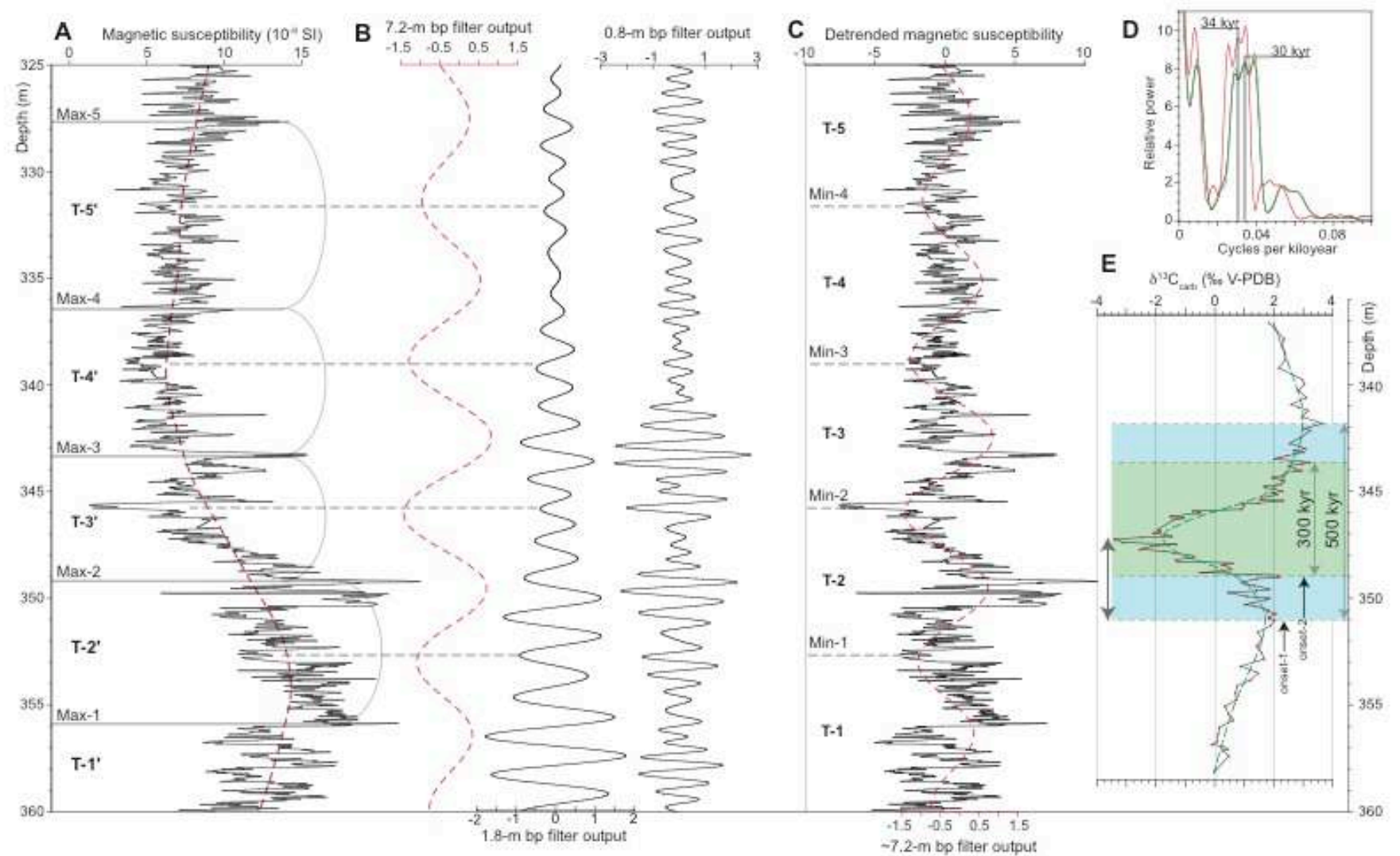

Figure 3: Detail of the Lower Toarcian showing astronomical calibration of the CIE. (A) Raw MS of the interval 325 to $360 \mathrm{~m}$, with a $30 \%$ weighted average smoothing. T-1' to T-5' are the interpreted $405 \mathrm{kyr}$ eccentricity cycles from MS maxima. (B) Bandpass (bp) filter outputs. Left: cutoff frequencies 0.088 and 0.168 cycles $/ \mathrm{m}$ to isolate $7.2-\mathrm{m}$ cycles (' $T$ ' cycles as in Fig. 2), which are interpreted as reflecting the $405 \mathrm{kyr}$ eccentricity cyclicity. Middle: cutoff frequencies 0.4 and 0.7 cycles $/ \mathrm{m}$ to isolate $1.8-\mathrm{m}$ cycles, interpreted as $\sim 100-\mathrm{kyr}$ eccentricity cycles. Right: cutoff frequencies 0.83 and $1.6 \mathrm{cycles} / \mathrm{m}$ to isolate $0.8-\mathrm{m}$ cycles interpreted as obliquity cycles. Spectral analysis of this interval is shown in Fig. S3. (C) Detrended MS by removal of the $30 \%$ weighted average shown in ' $A$ ', with the 7.2 $\mathrm{m}$ bandpass filter shown in ' $\mathrm{B}$ '. $\mathrm{T}-1$ to $\mathrm{T}-5$ are the interpreted $405 \mathrm{kyr}$ eccentricity cycles from MS minima (as in Fig. 2). (D) $2 \pi-M T M$ power spectrum of the tuned decreasing part of the CIE (indicated by vertical double-arrow in ' $E$ ') using $405 \mathrm{kyr}$ cycle maxima (red spectrum), $405 \mathrm{kyr}$ cycle minima (green spectrum), and both $405 \mathrm{kyr}$ cycle maxima and minima (black spectrum) (see text for details). (E) Bulk carbonate $\delta^{13} \mathrm{C}$ data are from Hermoso et al. (2009a), with a $20 \%$ weighted average of the series (dashed green curve). Two interpretations for the entire CIE: minimum ( 348.9 to $343.5 \mathrm{~m}$ ) and maximum (351.1 to $341.8 \mathrm{~m}$ ), which calibrate to a minimum $300 \mathrm{kyr}$ and a maximum $500 \mathrm{kyr}$ duration. The 'onset-2' position is as in Hermoso et al. (2009a,b). Vertical double-arrow represents the decreasing part of the $\mathrm{CIE}$. The extended $\delta^{13} \mathrm{C}$ curve shows that the $\mathrm{CIE}$ was a dramatic deviation from long-term $\delta^{13} \mathrm{C}$ variations (see Fig. 8), similar to the early Cenozoic PETM event (Boulila et al., 2012). This analysis favors the longer $500 \mathrm{kyr}$ duration that spans the entire CIE. 
The untuned power spectra (Figs. 5 and S2) indicate sub-precession scale ( 6.5 to $13.5 \mathrm{kyr})$ wavelengths varying from $\sim 0.12$ to $\sim 0.25 \mathrm{~m}$, precession-scale $(\sim 15.5$ to $\sim 24 \mathrm{kyr})$ wavelengths varying from $\sim 0.3$ to $\sim 0.53 \mathrm{~m}$, obliquity-scale $(\sim 30$ to $\sim 50 \mathrm{kyr}$ ) wavelengths from $\sim 0.46$ to $\sim 1 \mathrm{~m}$, and short eccentricity ( $\sim 94$ and $\sim 130 \mathrm{kyr}$ ) with mainly two wavelengths of $\sim 1.7$ and $\sim 2.7 \mathrm{~m}$ (Fig. 5). Filtering, power spectra, and visual inspection indicate that the $405 \mathrm{kyr}$ scale wavelengths vary from 6.5 to $9 \mathrm{~m}$ (e.g., Fig. 3).

The tuned power spectra show significant frequencies consistent with the La2004 astronomical model (Fig. 5C,D). The tuned spectrum of the entire MS series (Figs. 6 and S2) shows almost all predicted astronomical (Milankovitch) frequencies with TOAR-1 to TOAR- 6 cycles calibrating to $\sim 1.6$ Myr. This cyclicity likely reflects the $g_{4}-g_{3}$ eccentricity term, astronomically estimated as $\sim 2$ Myr (Fig. 5D, Section 5.2). The tuned spectrum of the lower part of the MS series shows significant periodicities at 129, 44, 21.4, $15.5 \mathrm{kyr}$ representing short eccentricity, obliquity, and precession components (Fig. 5C). Sub-precession cycles with significant power calibrate to 11.3-12.8 kyr. The tuned spectrum of the upper part of the MS series shows $94 \mathrm{kyr}$ (eccentricity), 33 and $26 \mathrm{kyr}$ (obliquity), 19.7 and $15.1 \mathrm{kyr}$ (precession) periodicities; sub-precession cycles with significant power calibrate to 11.1-13.8 kyr (Fig. 5D).

Finally, power spectra of the interval 325 to $360 \mathrm{~m}$ including the T-OAE (Figs. 3 and S3) indicate that obliquity signal is important. The untuned MS spectrum of this interval (Fig. S3A) shows significant peaks in the sub-precession, precession, obliquity, and eccentricity bands. In particular, the obliquity band has a power level that is equal with that of the short eccentricity. The tuned spectrum (Fig. S3B) calibrates obliquity wavelengths $0.53-0.97 \mathrm{~m}$ to $30-55 \mathrm{kyr}$. Filtering shows that MS variations related to obliquity-scale cycles are specifically concentrated in the interval 340 to $360 \mathrm{~m}$ that encompasses the CIE (Fig. 3). The strong expression of obliquity-scale cyclicity in the T-OAE interval was also noted in the Peniche (Portugal) and Dotternhausen (Germany) sections (Suan et al., 2008), although cyclostratigraphic misinterpretation of the analyzed sections is likely (Kemp et al., 2011; Section 5.1.2).

\subsection{Amplitude modulation (AM) analysis}

In the precession cycle band, AM results reveal several peaks concentrated on the $100 \mathrm{kyr}$ eccentricity band (Fig. S4). The $405 \mathrm{kyr}$ eccentricity band is also recovered but with a slightly longer mean period (440 kyr). Two well defined peaks at 199 and $260 \mathrm{kyr}$ do not show similarities with the astronomical model. These peaks may correspond to harmonics of the $100 \mathrm{kyr}$ eccentricity. At very low frequencies, two strong peaks of 3250 and $1400 \mathrm{kyr}$ correspond likely to very long eccentricity terms (see below).

In the eccentricity cycle band, the lowpass-filtered MS series shows strong short eccentricity cycles bundled by the $405 \mathrm{kyr}$ cycles (T-1 to T-21) throughout TOAR-1 to TOAR-6 cycles (Fig. 4). Spectral analysis of the amplitude envelope of the MS short eccentricity band reveals several peaks consistent with orbital eccentricity terms (Fig. S5). MS periods 196 and $221 \mathrm{kyr}$ correspond to astronomical periods of 202 and $225 \mathrm{kyr}$. The $400 \mathrm{kyr}$ band is characterized by a triplet of 342,372 and $409 \mathrm{kyr}$ periods, that likely reflect 337, 405 and $495 \mathrm{kyr}$ eccentricity terms. Two MS peaks 606 and 862 kyr with an average of $734 \mathrm{kyr}$ may indicate the $681 \mathrm{kyr}$ eccentricity term. The $2039 \mathrm{kyr}$ MS peak with high power corresponds to the $g_{4}-g_{3}$ eccentricity term modeled as $2042 \mathrm{kyr}$. This component is, however, estimated in the MS data as $1650 \mathrm{kyr}$ (Figs. 6 and S2), and corresponds to the TOAR-1 to TOAR-6 cycles. This may also be represented by the peak at $1400 \mathrm{kyr}$ in the AM series of the precession index (Fig. S4). Finally, the peak with the highest power is centered on a $3312 \mathrm{kyr}$ period. A similar component is detected with the highest power in the AM time series of the precession index (Fig. S4). Power spectra of the zero-padded tuned MS (Fig. 6) show well defined peaks centered on periods of $\sim 1.6$ and $\sim 3.5 \mathrm{Myr}$. This is a further confirmation of the presence of these low-frequency cycles. The 1.6 Myr modulating the precession and the short eccentricity cycle bands correspond to the $g_{4}-g_{3}$ eccentricity term. The 3.5 Myr period is not present in the theoretical astronomical spectrum (e.g., Fig. $5 \mathrm{E}$ ). It is, however, highlighted by lowpass filtering of the orbital eccentricity (Fig. S6), and its periodicity is estimated as 3.2 Myr for the interval 170 to $195 \mathrm{Ma}$. In fact, this cyclicity corresponds to a very long- 
period eccentricity component, which has the same origin as $g_{4}-g_{3}$ (Laskar, 1990). The period of this component is unstable, and any deviation of the 2.4 Myr (Cenozoic mean value) eccentricity term would also be expected to occur in the very long $4.5 \mathrm{Myr}$ eccentricity (Cenozoic mean value, J. Laskar pers. Comm.). Results of evolutive harmonic analysis (Fig. 7) shows a continuous spectral line depicting the $\sim 1.6$ Myr oscillations. The 100 and $405 \mathrm{kyr}$ eccentricity components are also detected but with discontinuous lines. There is a remarkable difference between the amplitude spectrograms of the tuned MS and of the orbital eccentricity: the $405 \mathrm{kyr}$ related $\mathrm{g}_{2}-\mathrm{g}_{5}$ eccentricity component is the strongest in the orbital theory, while the $1.6 \mathrm{Myr}$ related $\mathrm{g}_{4}-\mathrm{g}_{3}$ eccentricity component is the strongest in the MS signal.

In summary, AM analysis and lowpass filtering highlight MS variations that are analogous to the orbital eccentricity terms. These similarities between low-frequency MS variations and orbital eccentricity terms suggest that energy transfer from precession index cycles into eccentricity modulation cycles, as a result of rectification (Weedon, 2003), is the main process that explains the strong expression of eccentricity in the MS variations. Furthermore, the expression of low-amplitude eccentricity terms $(\sim 2$ Myr and $\sim 3.2$ Myr related to $g_{4}-g_{3}$ ) in the MS variations ( 1.6 Myr and 3.5 Myr, respectively) with the highest power is additional evidence for energy transfer from high to low frequencies (e.g., Huybers and Wunsch, 2003; Laepple and Lohmann, 2009; Boulila et al., 2012).

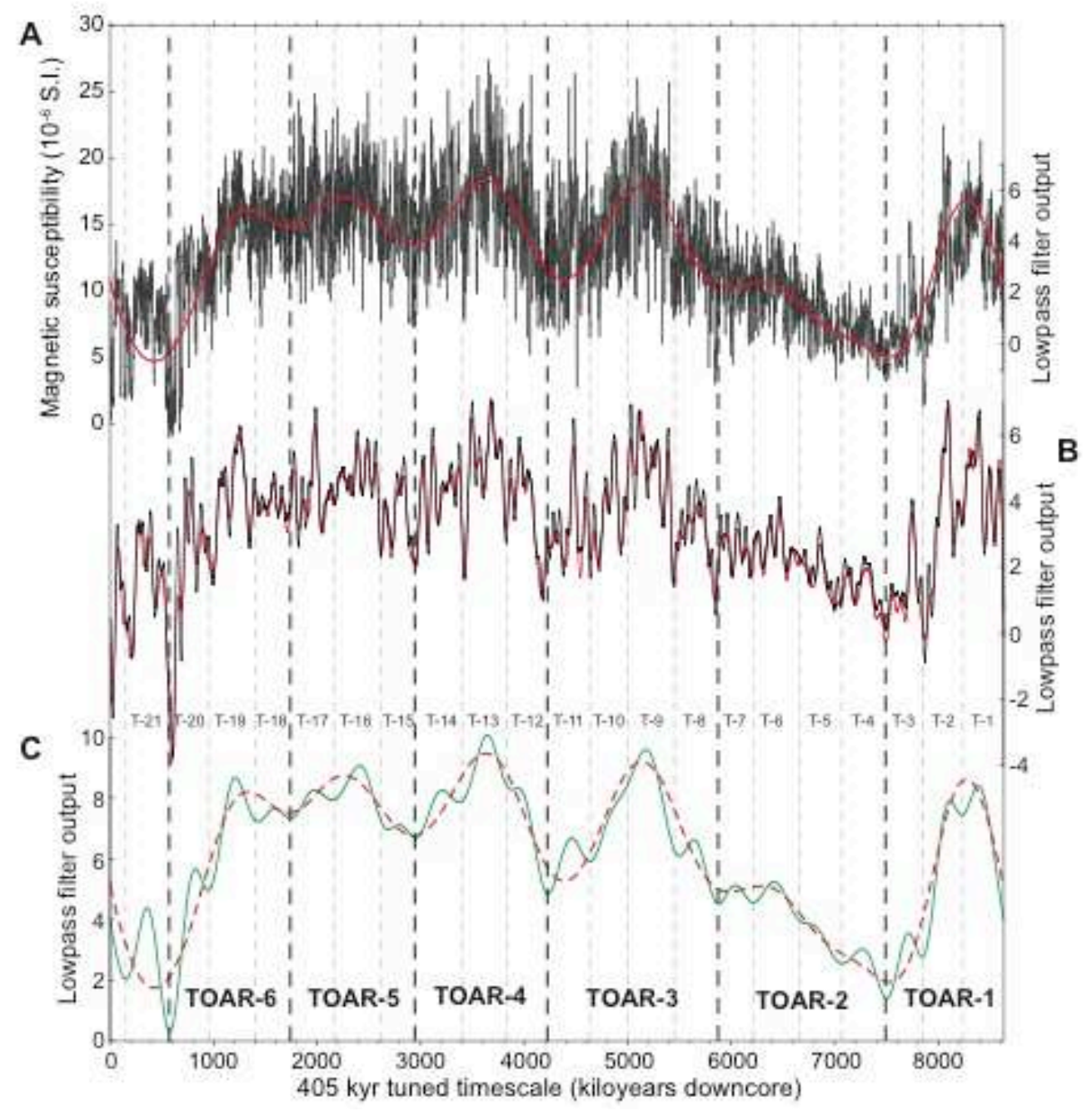

Figure 4: Lowpass filtering of the $405 \mathrm{kyr}$ tuned MS series using the Taner filter (Taner, 2000). (A) Tuned MS series. (B) Lowpass filter output to extract $100 \mathrm{kyr}$ eccentricity and longer periods, with two different cutoff frequencies: 0.017 cycles/kyr (black line), and 0.012 cycles/kyr (red line). (C) Lowpass filter outputs to extract 400 kyr eccentricity and longer periods (0.0035 cycles/kyr, green line), and $1.6 \mathrm{Myr}$ eccentricity and longer periods (0.00125 cycles/kyr, dashed red line). TOAR-1 to TOAR-6 cycles, and T-1 to T-21 cycles are the interpreted 1.6 Myr and 405 kyr eccentricity cyclicities, respectively, as in Fig. 2. 

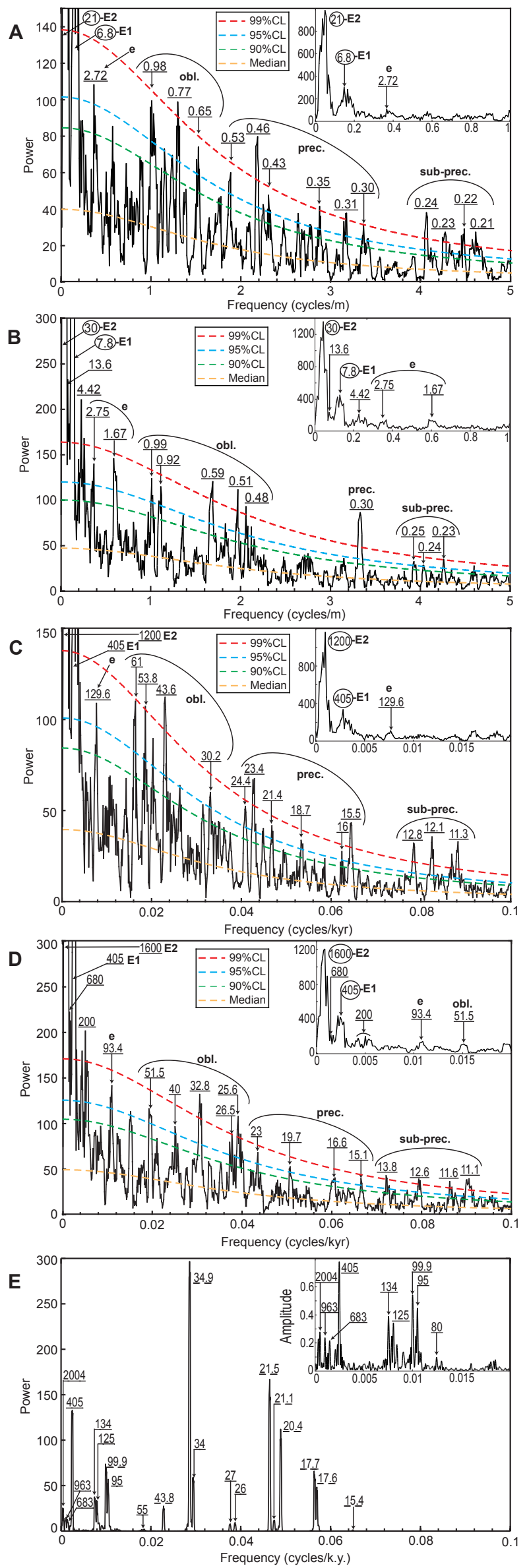
Figure 5: $2 \pi$ MTM power spectra for two intervals of the untuned and tuned MS data. (A) Untuned interval TOAR-1 to TOAR-3 (360 m to $276.5 \mathrm{~m}$, see Fig. 2) with the two high power ( 1000 and $\sim 300)$ peaks in the low frequencies (21- and 6.8-m wavelengths) truncated to emphasize the high-frequency portion of the spectrum. Inset: spectrum over $[0,1 \mathrm{cycles} / \mathrm{m}]$ expands the low-frequency spectrum. (B) Untuned interval TOAR-4 to the top of the stage (276.5 m to $194.55 \mathrm{~m}$, see Fig. 2), with the two high-power ( 1350 and $\sim 450)$ peaks in the lower frequencies (21and $6.8-\mathrm{m}$ wavelengths) truncated to emphasize the high-frequency portion of the spectrum. Inset: spectrum over $[0,1 \mathrm{cycles} / \mathrm{m}]$ to show the low-frequency portion of the truncated spectrum. (C) Tuned interval TOAR-1 to TOAR-3 with the two high-power ( 1000 and 300$)$ peaks in the low frequencies (1200- and 450-kyr periods) truncated to emphasize the high-frequency portion of the spectrum. Inset: spectrum over [0, $0.02 \mathrm{cycles} / \mathrm{kyr}]$ expands the lowfrequency spectrum. (D) Tuned interval TOAR-4 to the top of the stage with the two high-power ( 1350 and $\sim 450)$ peaks in the lower frequencies (1200- and 450-kyr periods) truncated to emphasize the high-frequency portion of the spectrum. Inset: spectrum over [0, 0.02 cycles/kyr] to show the low-frequency portion of the truncated spectrum. (E) Spectrum of La2004 astronomical parameters over $183 \mathrm{Ma}$ to $176 \mathrm{Ma}$ in ETP format (e.g., Imbrie et al., 1984). Inset: amplitude spectrum over [0, 0.02 cycles/kyr] expands the low-frequency spectrum. Symbols: $g_{4}-g_{3}$ eccentricity term (E2), $g_{2}-g_{5}$ (405 kyr) eccentricity term (E1), short eccentricity ( 100 kyr) term (e), obliquity (Obl.), precession (prec.), sub-Milankovitch or sub-precession (sub-prec.). For all spectra, robust red noise models used linear fitting and median filtering over $20 \%$ of the Nyquist frequencies. Most peaks exceeding $99 \%$ and $95 \%$ CL are labelled in meter in the untuned spectra and in kyr in the tuned spectra.

\subsection{Astronomical calibration of the Toarcian substages, the recognized ammonite zones, and the duration of CIE}

We used the $405 \mathrm{kyr}$ tuned timescale to infer durations to the Toarcian substages and ammonite zones in the Sancerre core. We projected the $405 \mathrm{kyr}$ timescale onto the ammonite zone boundaries (Fig. 2). In Table 1, we consider two possible duration estimates (maximum and minimum) since there are stratigraphic uncertainties in the ammonite zone boundaries. For example, the lower and upper boundaries of the Tenuicostatum Zone are not well recognized; thus, minimum and maximum durations are given as 0.04 and $0.09 \mathrm{Myr}$, respectively. The same procedure is applied to the Toarcian substages (Fig. 2). In the Sancerre core, there are two interpretations for the stratigraphic position of the onset of the CIE: $348.9 \mathrm{~m}$ and $351.1 \mathrm{~m}$ which calibrate respectively to $8020 \mathrm{kyr}$ and $8150 \mathrm{kyr}$ in the $405 \mathrm{kyr}$ timescale (Fig. 3). Considering the most likely position of the onset of CIE at Sancerre, i.e. $351.1 \mathrm{~m}$, the $405 \mathrm{kyr}$ timescale indicates a duration of $500 \mathrm{kyr}$ for the CIE. Even if this duration seems to be more realistic than the other interpretation (Section 5.1), we provide in Fig. 3 the two alternatives: minimum (300 kyr) and maximum (500 kyr) durations.

\section{Discussion}

\subsection{The Toarcian timescale, CIE duration, and comparison with previous studies}

\subsubsection{The Toarcian timescale}

The recent Geologic Time Scale, GTS2012 (Gradstein et al., 2012) adopted our 405 kyr tuning of magnetic susceptibility at Sancerre (Huang et al., 2010, see p.760 in GTS2012) but unfortunately this was applied to a poorly constrained biostratigraphic framework (Lorenz et al., 1987, 1991), conjointly with selected radio-isotopic ages to infer durations of Toarcian ammonite zones (Gradstein et al., 2012, their Table 26.3). Our revised ammonite biostratigraphic framework (Section 2, Plate S1) shows serious differences with the old framework (Lorenz et al., 1987, 1991). Therefore, we see that it is reasonable to compare our results with the previous Geologic Time Scale 2004, GTS2004 (Gradstein et al., 2004). In Table 1, we compare our duration estimates with those reported in GTS2004. Our estimated duration of the Serpentinum Zone is similar to that reported in GTS2004. However, durations of Tenuicostatum, Bifrons, and Aalensis zones differ significantly. The duration of the Lower Toarcian (1.70 to $1.88 \mathrm{Myr}$ ) is in agreement with GTS2004 (1.8 Myr). Also, durations of the Middle and Upper Toarcian (4.35 to 5.19 
Myr and 1.23 to $2.13 \mathrm{Myr}$, respectively) are significantly different from GTS2004 (0.7 Myr and 4.9 Myr, respectively).

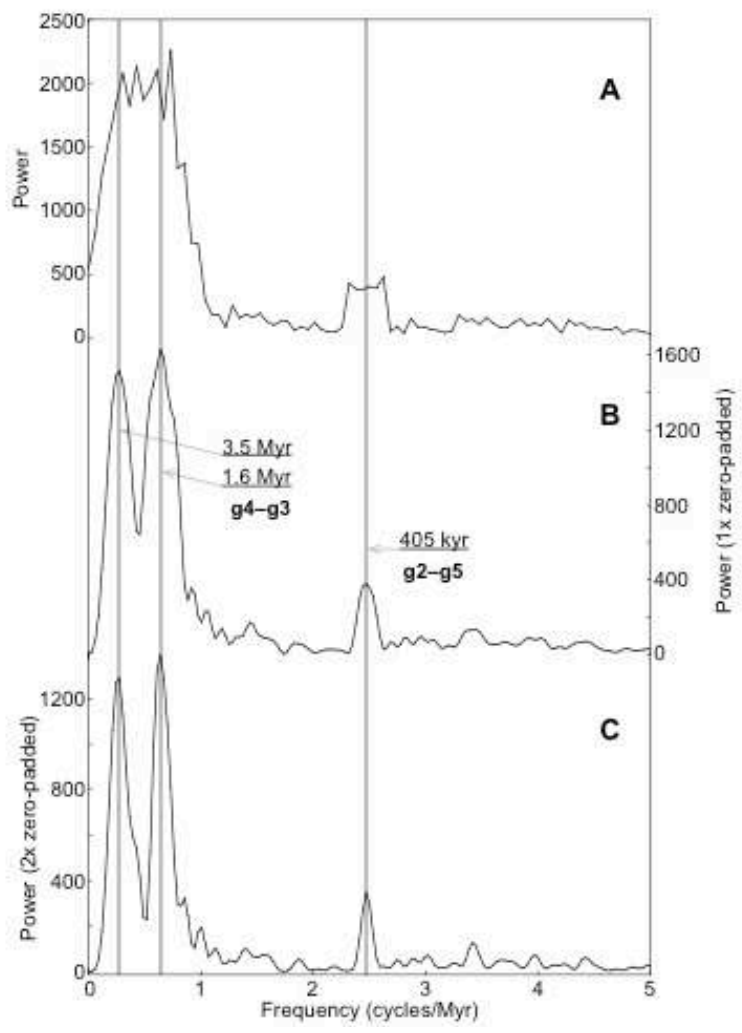

Figure 6: $2 \pi-M T M$ power spectra of the tuned MS data. (A) Spectrum of the detrended tuned MS. (B) Spectrum of the $1 \mathrm{x}$ zero-padded tuned MS. (C) Spectrum of the $2 \mathrm{x}$ zero-padded MS. Zero-padding allows a more refined determination of the frequencies. The strongest peak at the lowest frequency in ' $A$ ' is split into two peaks depicting the 1.6 and 3.5 Myr cyclicities related to $g_{4}-g_{3}$ eccentricity components.

Our 8.3 Myr estimate for the Toarcian Stage is close to that of GTS2004, which uses cyclostratigraphic estimates as follows. Astronomically forced cyclic carbonates of the Sogno Formation in northern Italy yielded a duration of $11.37 \pm 0.05(1 \sigma)$ Myr for the combined Toarcian-Aalenian Stages (Hinnov and Park, 1999). Unpublished cyclostratigraphic results from pelagic strata at Bugarone, central Italy (in Gradstein et al., 2004), suggests that the Aalenian spans $4 \mathrm{Myr}$, and thus a duration for the Toarcian is estimated as 7.4 Myr. Therefore, durations of the four upper Toarcian ammonite zones were proportionally scaled relative to equal subzones, and durations of the four lower ones were assessed by applying linear fits to the strontium isotopic variation within certain intervals (Gradstein et al., 2004, their Table 18.2 from McArthur et al., 2000).

In the present study we provide, for the first time, direct astronomical estimates of the durations of the substages and four ammonite zones (Tenuicostatum, Serpentinum, Bifrons and Aalensis Zones) of the Toarcian Stage, pointing to significant differences with those reported in GTS2004 (Table 1). With the exception of Tenuicostatum Zone, which seems to be too short (0.04-0.09 Myr vs. 0.3 Myr in GTS2004), our cyclostratigraphic estimates could be used in the future generation of GTS. The recent GTS2012 used our estimate of $~ 8.3$ Myr from preliminary results (Huang et al., 2010) and added a 200 kyr duration assuming a condensation at the basal Tenuicostatum Zone in Sancerre, for a total duration of 8.6 Myr (Ogg and Hinnov, 2012, their Table 26.3). The hypothesis of a condensation in the lower Toarcian in Sancerre is likely given that the Tenuicostatum Zone is reduced in thickness $(1.8$ to $7.8 \mathrm{~m}$, Fig. 1), although our cyclostratigraphic results do not indicate a significant hiatus at this level (e.g., Fig. 4). In contrast, the Polymorphum Mediterranean equivalent Zone in the Amellago section (Morocco) is $\sim 65 \mathrm{~m}$ thick (Bodin et al., 2010). Also, a duration of $0.8 \mathrm{Myr}$ for the Polymorphum Zone was inferred from 
the Peniche section, Portugal (Suan et al., 2008), although a problem in their cyclostratigraphic interpretation is likely (Kemp et al., 2011; see below, Section 5.1.2). In place of adding an arbitrary 200 kyr duration to the basal Toarcian Stage to compensate for a possible condensation (Ogg and Hinnov, 2012) we suggest future high-resolution cyclostratigraphic studies from thick Lower Toarcian sections (e.g., the Amellago section, Morocco) to constrain the chronology of the Tenuicostatum Zone.

The present Toarcian astronomical timescale has consequences for the global carbon cycle (Section 5.1.2), constraints on astronomical theory (Section 5.2), sequence stratigraphic hierarchy (Section 5.3), and climate dynamics and biodiversity evolution during the Jurassic Period (Cecca and Macchioni, 2004; Dera et al., 2011).

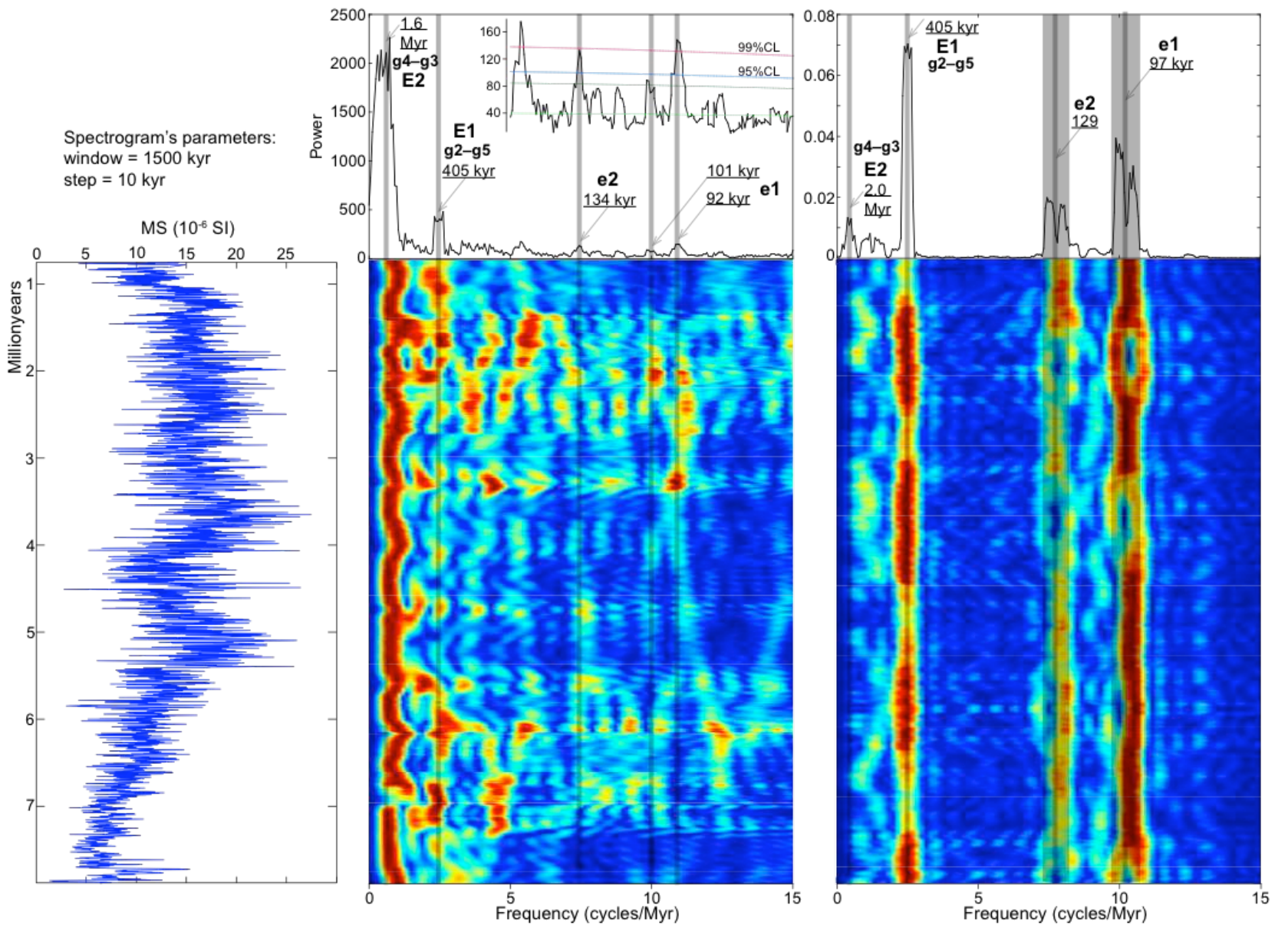

Figure 7: Evolutive FFT analysis of the tuned MS time series and the La2010d orbital eccentricity solution of Laskar et al. (2011) for the Toarcian Stage. Both are computed with a $1500 \mathrm{kyr}$ window and a step of $10 \mathrm{kyr}$. The individual windows are zero-padded to $5 \mathrm{x}$ the $1500 \mathrm{kyr}$ length. The $405 \mathrm{kyr}$ related $\mathrm{g}_{2}-\mathrm{g}_{5}$ eccentricity component is the strongest in astronomical theory, while the $1.6 \mathrm{Myr}$ related $g_{4}-g_{3}$ eccentricity component is the strongest in the MS signal. Inset: an expanded view of the MS spectrum over [0.005, $0.015 \mathrm{cycles} / \mathrm{kyr}]$ with confidence levels (CL) to highlight the detection of the short eccentricity components.

\subsubsection{CIE duration}

The $405 \mathrm{kyr}$ timescale assigns a duration of 300 to $500 \mathrm{kyr}$ to the CIE (Fig. 3). This duration is in agreement with the correlative CIE equivalent in Yorkshire, England ( 300 kyr, Kemp et al., 2005), but differs significantly from that in the two sections at Peniche, Portugal and Dotternhausen, Germany ( $900 \mathrm{kyr}$, Suan et al., 2008). Recently, Kemp et al. (2011) revised the astronomical timescale of the Peniche and Yorkshire sections. They suggested that the $75-\mathrm{cm}$ cyclicity at Yorkshire and their $\sim 143 \mathrm{~cm}$ thick equivalents at Peniche may correspond to precession or obliquity forcing rather than short 
eccentricity cycles as suggested by Suan et al. (2008). Kemp et al. (2005) suggested that this cyclicity was precession-driven, and they considered a mean period of $20 \mathrm{kyr}$ for the cycles. They counted 20 precession cycles encompassing the CIE, implying a $400 \mathrm{kyr}$ duration. Laskar et al.'s (2004) model for Toarcian time indicates a mean precession period of $19.5 \mathrm{kyr}$ and a mean obliquity period of $35 \mathrm{kyr}$. This results in a duration of $292 \mathrm{kyr}$ for a precession forcing hypothesis, and $525 \mathrm{kyr}$ for an obliquity forcing hypothesis (Kemp et al., 2011). These estimates are again close to ours, but are very different from Suan et al.'s (2008) estimate.

The $405 \mathrm{kyr}$ timescale indicates a strong expression of obliquity cycles within the interval that includes the T-OAE (Section 4.1). This suggests that obliquity may play a significant role in climatic and paleoenvironmental changes during the T-OAE. Here we used the $405 \mathrm{kyr}$ MS timescale from the interval 325 to $360 \mathrm{~m}$ including the CIE to indirectly time-calibrate the high-frequency $\delta^{13} \mathrm{C}$ cycles, well expressed within the decreasing part of the CIE (Fig. 3). In detail, we compared three $405 \mathrm{kyr}$ tuning tests: using only maxima, only minima, and both maxima and minima of the $405 \mathrm{kyr}$ MS cycles. The former calibrates high-frequency $\delta^{13} \mathrm{C}$ cycles to $34 \mathrm{kyr}$ periodicity, while the two latter calibrate them to $30 \mathrm{kyr}$ (Fig. 3D). Accordingly, the high-frequency $\delta^{13} \mathrm{C}$ cycles are most likely an expression of Toarcian obliquity forcing, in accordance with one of the options of Kemp et al. (2011). These high-frequency $\delta^{13} \mathrm{C}$ cycles were also recorded in proximal environments, and have been demonstrated to be concomitant with well-expressed sea-level sequences (Hesselbo and Pienkowski, 2011). The $\delta^{13} \mathrm{C}$ cycles are most likely the expression of obliquity forcing, although Hesselbo and Pienkowski (2011) used a previous cyclostratigraphic framework (Suan et al., 2008) to interpret them as corresponding to short (100 kyr) eccentricity forcing.

We propose a correlation among the three key sections at Sancerre (France), Yorkshire (England) and Peniche (Portugal) (Fig. 8). We use the clearly expressed $\delta^{13} \mathrm{C}$ obliquity cycles at Sancerre and Yorkshire. Peniche $\delta^{13} \mathrm{C}$ data do not record high-frequency $\delta^{13} \mathrm{C}$ cycles; instead, we use carbonate content $\left(\mathrm{CaCO}_{3}\right)$ variations (as in Kemp et al., 2011, their Figure 8) that show evidence of well-expressed $\mathrm{CaCO}_{3}$ obliquity cycles. The decreasing part of $\mathrm{CIE}$ at the three sections is characterized by strong expression of obliquity cycles permitting a detailed correlation. However, the increasing part of $\mathrm{CIE}$ does not show high-frequency $\delta^{13} \mathrm{C}$ cycles. It is placed tentatively as corresponding to the end of CIE (Fig. 8).
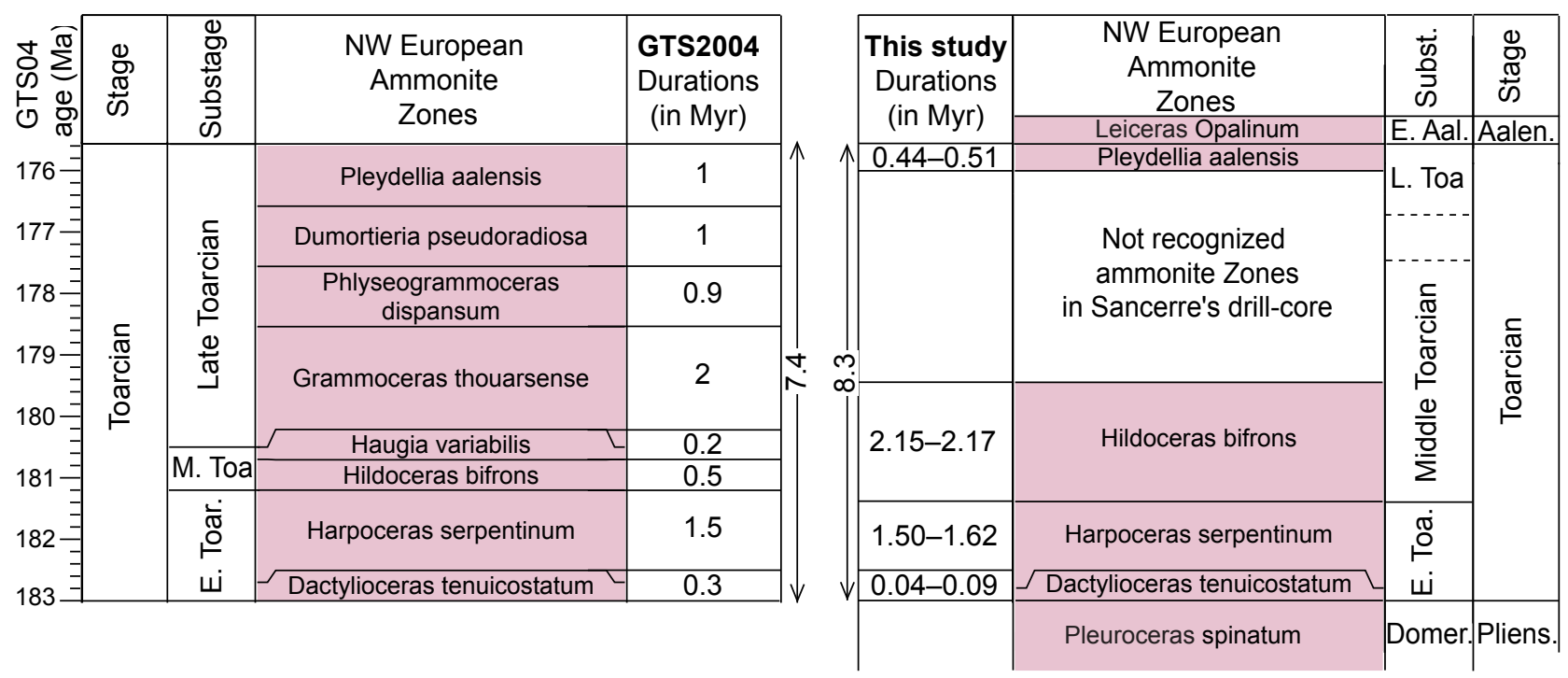

Table 1: Comparison of ammonite zone duration estimates from GTS2004 (Gradstein et al., 2004), and from the astronomical calibration in this study. 


\subsection{The $\sim 1.6$ Myr magnetic susceptibility (MS) cycles related to ' $g_{4}-g_{3}$ ' eccentricity modulation}

The planetary secular frequencies that control Earth's orbital eccentricity cycles (Laskar et al., 2004) are unstable during geologic time. The $g_{4}-g_{3}$ term has a mean periodicity of $\sim 2.4$ Myr in the Cenozoic, but in the Mesozoic its value is not constrained by the astronomical models. The only possible way to constrain the periodicity of $g_{4}-g_{3}$ in the astronomical models is from the geological record. Laskar et al. (2004) recommended tuning Mesozoic sedimentary records to the $405 \mathrm{kyr}$ stable period $\left(g_{2}-g_{5}\right)$, then infer the mean period of the $g_{4}-g_{3}$ component from long-period sedimentary cycles. Our $405 \mathrm{kyr}$ tuning of the MS record assigns a mean period of $~ 1.6$ Myr to the TOAR-1 to TOAR-6 cycles, which we interpret as evidence for the $g_{4}-g_{3}$ eccentricity term. In addition, AM analysis and lowpass filtering of the $405 \mathrm{kyr}$ tuned MS series indicate a consistent relationship between T-1 to T-21 (405 kyr cycles) and TOAR-1 to TOAR-6 cycles, supporting the idea that the $\sim 1.6$ Myr cycles correspond to $g_{4}-g_{3}$ term (Figs. 4 and S5).

The $g_{4}-g_{3}$ term is related to orbital resonance between Earth and Mars, and has been demonstrated to undergo chaotic motion during the geologic past, with a variable periodicity during Mesozoic Era (Laskar et al., 2004). The La2004 model predicts a Toarcian $g_{4}-g_{3}$ periodicity of $\sim 2 \mathrm{Myr}$ (e.g., Fig. S5), while its Cenozoic value is $\sim 2.4$ Myr. Only four previous cyclostratigraphic studies have dealt with $g_{4}-g_{3}$ period estimates in Mesozoic strata. Olsen and Kent (1999) estimated a period of 1.75 Myr from Late Triassic sequences. Similarly, Ikeda et al. (2010) found a $1.8 \mathrm{Myr}$ term in the Late Triassic Inuyama deep-sea chert sequence of Japan. Boulila et al. (2010), and Huang et al. (2010a) assigned a period of $\sim 2$ Myr to Oxfordian-Kimmeridgian (Late Jurassic) sequences. Finally, Huang et al. (2010b) detected a period of 1.6 Myr in the Aptian (Early Cretaceous). Our estimate concurs with previous studies for a shortened $g_{4}-g_{3}$ periodicity in the Mesozoic, and supports astronomical modeling for instability in the $g_{4}-g_{3}$ eccentricity term.

\subsection{Third-order eustatic sequences and the 1.6 Myr magnetic susceptibility (MS) cycles (TOAR- 1 to TOAR-6)}

Global sea-level (eustatic) change is one of the major controls on the sedimentary record in tune with a wide temporal band (e.g., Sloss, 1963; Vail et al., 1977; Kominz et al., 1998; Miller et al., 2005). Vail et al. (1977) divided sea-level depositional sequences temporally into six orders ranging from tens of millions years (first- and second-order) to a few tens of thousands years (sixth order). First- and second-order sequences are attributed to tectono-eustatic changes (mantle convection and plate tectonics). Fourth, fifth, and sixth orders were linked to climato-eustatic changes driven by Earth's orbital parameters. Third-order sequences were often related to both tectonic and climatic influences (e.g., Vail et al., 1991).

Many studies have suggested tectonics as the major driver of third-order sequences (e.g., Cloetingh, 1988; Miall, 1990; Karner et al., 1993; Dewey and Pitman, 1998; Lovell, 2010), though these mechanisms fail to explain global sea-level changes. Recent studies have argued that orbitally forced climate is the main control of third-order eustatic sequences via glacioeustasy, thermoeustasy, and/or other processes (e.g., Lourens and Hilgen, 1997; Grant et al., 1999; Strasser et al., 2000; Gale et al., 2002, 2008; Matthews and Frohlich, 2002; Boulila et al., 2010, 2011).

The good expression (with relatively important impedance/amplitude) of third-order sea-level sequences in the sedimentary seismic and well-log records makes them of particular interest in petroleum exploration researches, considering them as the basic sediment blocks for correlations (Vail et al., 1977; Haq et al., 1987). In addition, the third-order sequences constitute the backbones of most of eustatic charts and represent the building blocks of the longer term sequences and are correlatable elementary units at the craton scale (Hardenbol et al., 1998). Therefore, timing and origin of these sequences are fundamental. High-resolution cyclostratigraphic results when compared to sequence stratigraphic data could constrain duration and thus origin of third-order sequences (Boulila et al., 2011). 


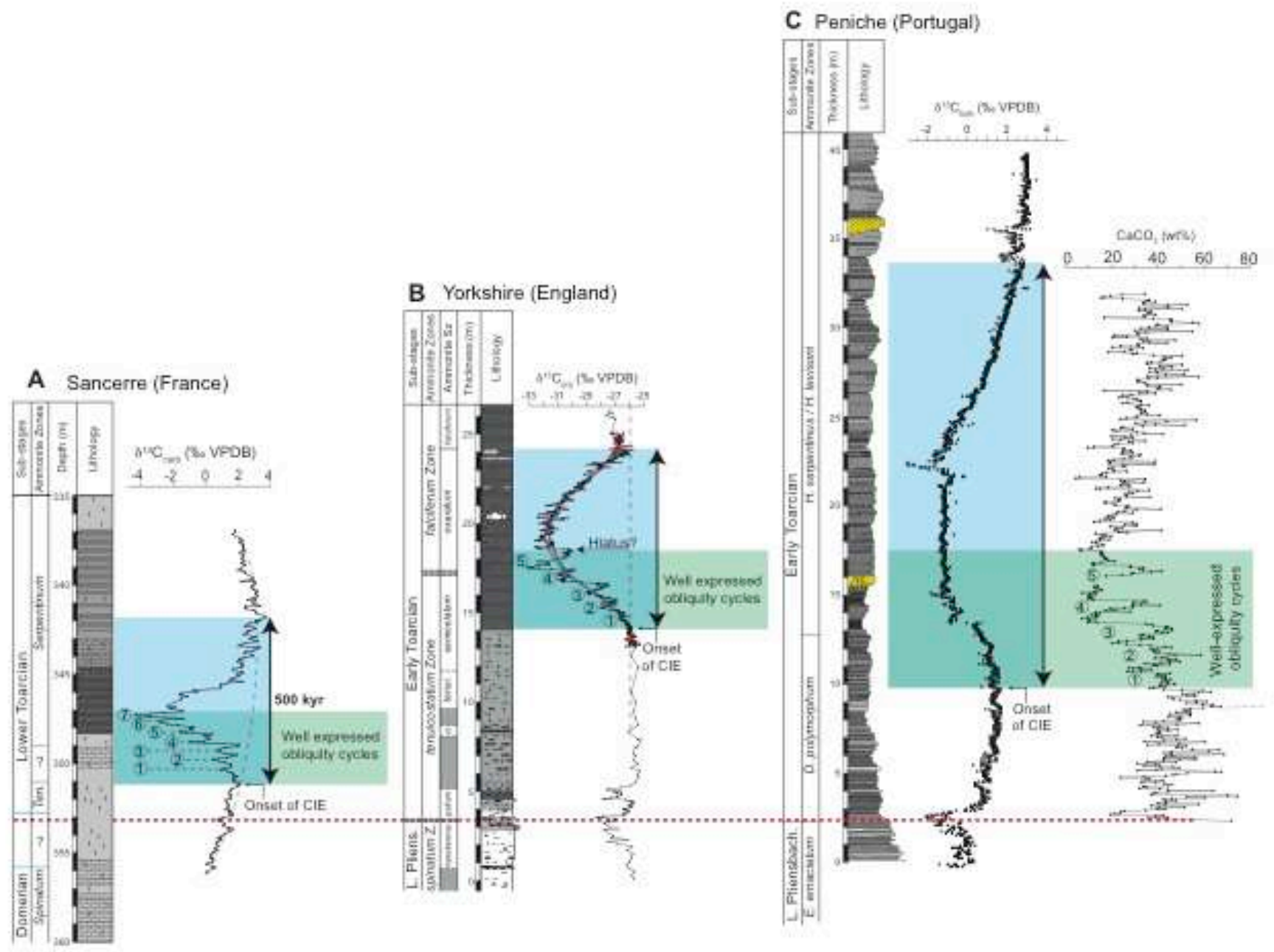

Figure 8: Correlation of the Toarcian CIE at Sancerre (France), Yorkshire (England), and Peniche (Portugal) sections. (A) Sancerre data are from Hermoso et al. (2009a); duration of the CIE is from this study. (B) Yorkshire stratigraphic log is from Hesselbo and Jenkyns (1995), and Littler et al. (2010), $\delta^{13} \mathrm{C}$ data are from Kemp et al. (2005), possible hiatus is according to Kemp et al. (2011). (C) Peniche stratigraphic log is from Mattioli et al. (2008), $\delta^{13} \mathrm{C}$ data are from Hesselbo et al. (2007), $\mathrm{CaCO}_{3}$ data are from Suan et al. (2008). Note that the three sections are reset to the same stratigraphic scale, and anchored at the Pliensbachian-Toarcian (PI/Toa) boundary. This boundary is defined with an interval of uncertainty at Sancerre; here we tentatively place it according to the $\delta^{13} \mathrm{C}$ shift highlighted in the two other sections (Peniche and Yorkshire). Interpreted obliquity cycles within the decreasing part of CIE (DP-CIE) are numbered from 1 to 7 , and correlated within the three sections. Note that the apparently most complete DP-CIE is at Sancerre, although it represents the lowest sedimentation rate. Note also that the CIE shows clearly a dramatic deviation from the long-term $\delta^{13} \mathrm{C}$ variations (indicated by grey-dashed arc).

Despite the slight high-frequency change in carbonate content in the Sancerre core, which is not discernable in the core description, we have noted that, at lower frequencies, some intervals of carbonate-rich marls record the lowest MS values (Fig. 2). We suggest that long-term MS variations in the Sancerre core reflect oscillations in clay versus carbonate content which were, in turn, controlled by sea-level fluctuations. This hypothesis is supported by hysteresis measurements (Section 3), which show a paramagnetic behavior caused by clay minerals. Another evidence for sea-level control of the lithological expression comes from the good correspondence between long-term MS cycles and sealevel sequences deduced from sediment and facies evolution in both proximal and distal environments (Graciansky et al., 1998).

Below we compare third-order sequences from the reference eustatic chart (Hardenbol et al., 
1998) with our Toarcian MS cycles. In particular, the strong 1.6 Myr MS cycles (TOAR-1 to TOAR-6) attributed to long-period $\left(g_{4}-g_{3}\right)$ eccentricity cycles are comparable to third-order sequences as follows (Table 2).

The Toarcian Stage contains six complete eustatic sequences (Toa1-Toa2, Toa2-Toa3, Toa3Toa4, Toa4-Toa5, Toa5-Toa6 and Toa6-Toa7), and two other incomplete ones (PI8-Toa1 and Toa7Aa1) in the European reference chart (Hardenbol et al., 1998). There the Toarcian sequences were defined from several sections (mainly in outcrops) in different locations in France (the southern France Basin, southern Massif Central, eastern Aquitaine in Quercy basin, and the Paris Basin and its surroundings: Graciansky et al., 1993, 1998; Rey and Cubaynes, 1991), and then were compared to those obtained from sections in the U.K. (Wessex, Cleveland and Hebrides basins: Hesselbo and Jenkyns, 1995, Hesselbo et al., 1998).

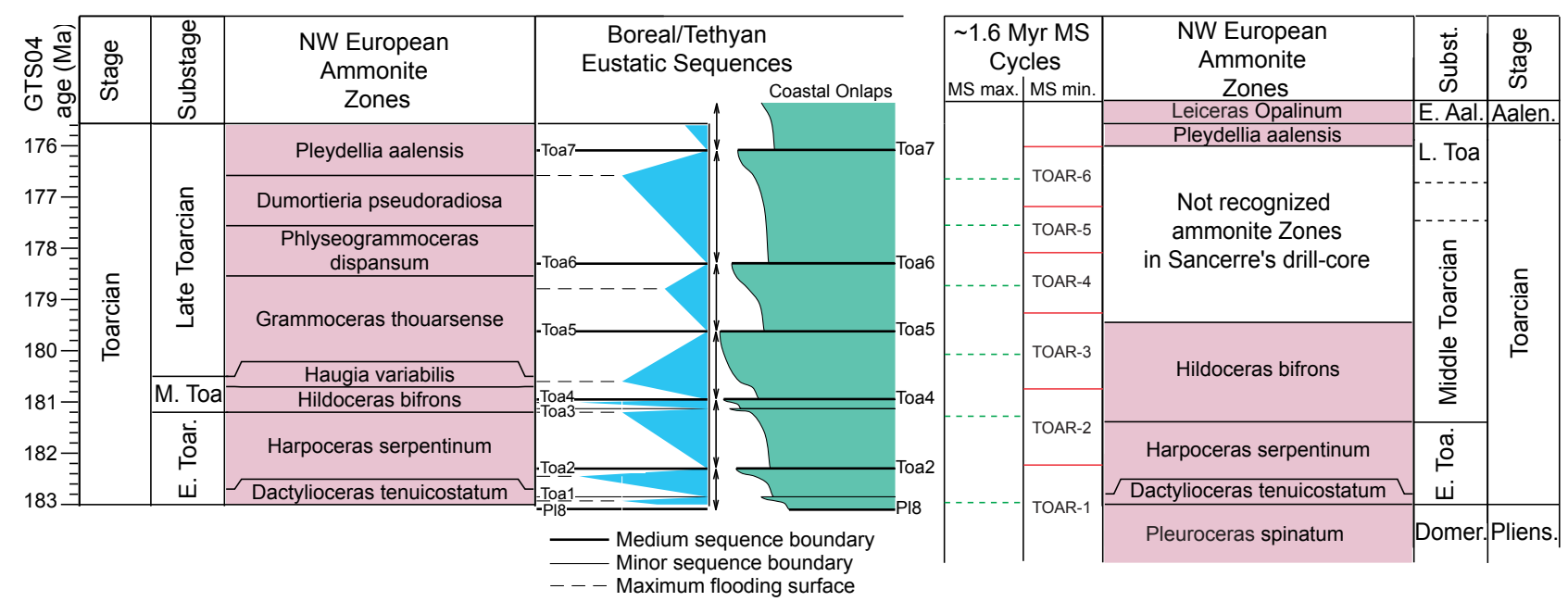

Table 2: Comparison between third-order eustatic sequences and the 1.6 Myr magnetic susceptibility (MS) cycles. (A) Ammonite biostratigraphy and sequence stratigraphic framework of the Toarcian Stage as defined in the European eustatic reference chart of Hardenbol et al. (1998), which is rescaled to GTS2004 (Gradstein et al., 2004); third-order sequences (i.e., medium) are marked by double arrows. (B) Ammonite biostratigraphy and $~ 1.6$ Myr TOAR cycles at Sancerre, in terms of minima and maxima of MS.

Hardenbol et al. (1998), who refer to Graciansky et al. (1998), considered only six of the eight Toarcian sequences (marked in Table 2 by vertical double arrows) as third-order sequences (i.e., medium); the two others are considered as minor sequences. The Toarcian Stage in the Sancerre section includes five complete long-term magnetic susceptibility (MS) cycles TOAR-2 to TOAR-6 and two incomplete ones TOAR-1 and a small part of a possible upper cycle (Table 2 and Fig. 2). The 1.6 Myr MS cycles and third-order sequences falls in the same temporal order and may be comparable (Supplementary File). Even if the third-order sequences were inferred, in part, from the Paris Basin, paleontological and sedimentological correlations between numerous shallow and deep marine sections in France and the U.K. indicate the global nature of these sequences, or at least that they are widespread at the scale of boreal and tethyan realms of the European basins (Hardenbol et al., 1998). In addition, the correspondence between the $\sim 1.6 \mathrm{Myr}$ MS related eccentricity cycles and third-order sequences favors a global origin. In the supplementary file, we compare the biostratigraphic positions of TOAR cycles, when available, with those of third-order eustatic sequences, and we summarized the main sedimentological features in the French sequences as described in the reference chart of Hardenbol et al. (1998), who refer to Graciansky et al. (1998).

In summary, the close correspondence between TOAR-1 to TOAR-6 MS cycles and third-order eustatic sequences (Table 2) provides compelling evidence that third-order sea-level fluctuations was astronomically paced in tune with $g_{4}-g_{3}$ eccentricity variations. Additionally, T-1 to T-21 MS cycles (Fig. 4) reflect the $g_{2}-g_{5} 405 \mathrm{kyr}$ eccentricity term (Sections 4.1 and 4.2 ), and are modulated by the $g_{4}-g_{3}$ 
eccentricity (e.g., Boulila et al., 2012 their Figure 6). Thus, T-1 to T-21 MS cycles would correspond to fourth-order eustatic sequences. We suggest that astro-climatic forcing exerts an hierarchical control on deep-sea marl sequences via sea-level change. This observation was extensively discussed in Boulila et al. (2011). Finally, our high-resolution cyclostratigraphic results suggest that the Sancerre TOAR cycles/sequences could represent, at the present time, a reference sequence stratigraphic framework for the Toarcian Stage. The Sancerre TOAR cycles should, however, be cross-checked in the future from other distant basins.

\section{Conclusions}

MS variations in the Toarcian marls of the Sancerre-Couy drill-core of the Paris Basin reveal superposed frequencies consistent with sub-Milankovitch and Milankovitch forcing (precession, obliquity, eccentricity). Long eccentricity terms $g_{2}-g_{5}$ and $g_{4}-g_{3}$ are documented with the highest MS amplitudes. The well-constrained $\mathrm{g}_{2}-\mathrm{g}_{5}$ eccentricity term, with a stable period of $405 \mathrm{kyr}$ for Cenozoic-Mesozoic times, is used as a metronome for astronomical calibration of this portion of Early Jurassic. The principal results of the $405 \mathrm{kyr}$ tuning are as follows:

- The Toarcian Stage is calibrated to a minimum duration of 8.3 Myr.

- Durations of the Tenuicostatum, Serpentinum, Bifrons, and Aalensis zones are 0.04-0.09 Myr, 1.50-2.17 Myr, 2.15-2.17 Myr, and 0.44-0.51 Myr, respectively. Durations of the Lower, Middle and Upper Toacian substages are 1.70-1.88 Myr, 4.35-5.19 Myr, and 1.23-2.13 Myr, respectively.

- The T-OAE CIE duration is estimated as 300-500 kyr.

- Periodicity of the high-frequency $\delta^{13} \mathrm{C}$ cycles within the decreasing part of the CIE is calibrated to 30 to $34 \mathrm{kyr}$, matching the predicted Toarcian obliquity period.

- The prominent $g_{4}-g_{3}$ MS cyclicity calibrates to a period of $\sim 1.6 \mathrm{Myr}$, which is shorter than the astronomically predicted $\sim 2.0 \mathrm{Myr}$, and the $\sim 2.4 \mathrm{Myr}$ stratigraphically detected occurrence in the Cenozoic. This supports astronomical modeling for the instability in the $g_{4}-g_{3}$ term from chaotic motion of the inner planets.

The 1.6 Myr MS cycles correspond to the third-order eustatic sequences of the European reference chart and constrains the sequence stratigraphic framework of the Toarcian Stage. We conclude that the Toarcian Sancerre marls were deposited continuously under astronomical forcing controls over many millions of years, resulting in an extraordinary record of direct climatic and eustatic responses to precession and obliquity, including their long-period modulations.

\section{Acknowledgments}

This work was supported by French ANR Grant ASTS-CM. We wish to thank J. Laskar for helpful discussions. B.G. gratefully acknowledges the BRGM for providing access to the Sancerre-Couy core. L.H. was supported by US National Science Foundation grant EAR-0718905. We are grateful to Editor Jean Lynch-Stieglitz, and thank the three reviewers for very helpful reviews that led to important revisions of our manuscript.

\section{References}

Bailey, T.R., Rosenthal, Y., McArthur, J.M., van de Schootbrugge, B., Thirlwall, M.F., 2003. Paleoceanographic changes of the Late Pliensbachian-Early Toarcian interval: a possible link to the genesis of an Oceanic Anoxic Event. Earth and Planetary Science Letters 212, 307-320.

Bodin, S., Mattioli, E., Fröhlich, S., Marshall, J.D., Boutib, L., Lahsini, S., Redfern, J., 2010. Toarcian carbon isotope shifts and nutrient changes from the Northern margin of Gondwana (High Atlas, Morocco, Jurassic): Palaeoenvironmental implications. Earth and Planetary Science Letters 297, 377-390.

Boulila, S., Galbrun, B., Hinnov, L.A., Collin, P.Y., Ogg, J.G., Fortwengler, D., Marchand, D., 2010. Milankovitch and sub-Milankovitch forcing of the Oxfordian (Late Jurassic) Terres Noires Formation (SE France) and global 
implications. Basin Research 22, 717-732.

Boulila S., Galbrun B., Laskar J., Pälike H., 2012. A $\sim 9$ myr cycle in Cenozoic $\delta^{13} \mathrm{C}$ record and long-term orbital eccentricity modulation. Is there a link? Earth Planet. Sci. Lett. 317-318, 273-281.

Boulila S., Galbrun B., Miller K.G., Pekar S.F., Browning J.V., Laskar J., Wright J.D. 2011. On the origin of Cenozoic and Mesozoic "third-order" eustatic sequences. Earth-Science Reviews 109, 94-112.

Bown, P.R., and Cooper, M.K.E., 1998. Jurassic, in Bown, P.R., ed., Calcareous Nannofossil Biostratigraphy: Chapman \& Hall/Kluwer, Dordrecht, Netherland, p. 34-85.

Cloetingh, S., 1988. Intraplate stresses: a tectonic cause for third-order cycles in apparent sea level? Society of Economic Paleontologists and Mineralogists Special Publication 42, 19-29.

Cohen, A.S., Coe, A.L., Kemp, D.B., 2007. The Late Palaeocene-Early Eocene and Toarcian (Early Jurassic) carbon isotope excursions: a comparison of their time scales, associated environmental changes, causes and consequences. Journal of the Geological Society [London] 164 (6), 1092-1108.

de Kaenel, E., Bergen, J.A., von Salis Perch-Nielsen, K., 1996. Jurassic calcareous nannofossil biostratigraphy of western Europe. Compilation of recent studies and calibration of bioevents. Bulletin de la Société Géologique de France 167, 15-28.

Delavenna, M.-F., Steinberg, M., Trauth, N., Holtzapffel, T., 1989. Influence des cycles eustatiques et de la tectonique synsédimentaire sur la minéralogie du Lias et du Dogger du forage de Sancerre-Couy (Cher). Programme Géologie profonde de la France. C. R. Acad. Sci. 308, 111-116.

Dera, G., Pucéat, E., Pellenard, P., Neige, P., Delsate, D., Joachimski, M.M., Reisberg, L., Martinez, M., 2009. Water mass exchange and variations in seawater temperature in the NW Tethys during the Early Jurassic: Evidence from neodymium and oxygen isotopes of fish teeth and belemnites. Earth and Planetary Science Letters 286, 198-207.

Dewey, J.F., Pitman, W.C., 1998. Seal-level changes: Mechanisms, magnitudes and rates. In: Pindell, J.L., Drake, C.L. (Eds.), Paleogeographic evolution and non-glacial eustasy, northern South America. SEPM (Soc. Sed. Geol.), Spec. Publ. 58, pp. 1-17.

Elmi, S., Gabilly, J., Mouterde, R., Rulleau, L., Rocha, R.B. 1994. L'étage Toarcien de l'Europe et de la Téthys : divisions et corrélations. Geobios, Mémoire Spécial 17, 149-159.

Elmi, S., Rulleau, L., Gabilly, J., Mouterde, R., 1997. Toarcien, in Cariou, E., Hantzpergue, P., eds., Biostratigraphie du Jurassique ouest-européen et méditerranéen: Pau, Bulletin du Centre de recherche ELF Exploration Production, mémoire 17, p. 25-36.

Ghil, M., Allen, R.M., Dettinger, M.D., Ide, K., Kondrashov, D., Mann, M.E., Robertson, A., Saunders, A., Tian, Y., Varadi, F., Yiou, P., 2002. Advanced spectral methods for climatic time series. Review of Geophysics 40, 1.1-1.41.

Gale, A.S., Hardenbol, J., Hathway, B., Kennedy, W.J., Young, J.R., Phansalkar, V., 2002. Global correlation of Cenomanian (Upper Cretaceous) sequences: Evidence for Milankovitch control on sea level. Geology 30, 291-294.

Gale, A.S., Voigt, S., Sageman, B.B., Kennedy, W.J., 2008. Eustatic sea-level record for the Cenomanian (Late Cretaceous) - Extension to the Western Interior Basin, USA. Geology 36, 859-862.

Gill, B.C., Lyons, T.W., Jenkyns, H.C., 2001. A global perturbation to the sulfur cycle during the Toarcian Oceanic Anoxic Event. Earth and Planetary Science Letters 312, 484-496.

Graciansky, P.C. de, Dardeau, G., Dumont, T., Jacquin, T., Marchand, D., Mouterde, R., Vail, P.R., 1993. Depositional sequence cycles, transgressive/regressive facies cycles and extensional tectonics: example from the Southern Sub-Alpine Jurassic basin. Bulletin de la Société Géologique de France, tome 164, p. 709-718.

Graciansky, P.C. de, Jacquin, T., Hesselbo, S.P., 1998, The Ligurian cycle: an overview of Lower Jurassic $2^{\text {nd }}$-order transgressive/regressive facies cycles in Western Europe, in Graciansky, P.C., Hardenbol, J., Jacquin, T., and Vail, P.R., eds., Mesozoic and Cenozoic Sequence Stratigraphy of European Basins: Tulsa, OK, SEPM Special Publication 60, p. 467-479.

Gradstein, F.M., Ogg, J.G., Smith, A.G., 2004. A Geologic Time Scale 2004. Cambridge University Press, 589 p.

Gradstein, F.M., Ogg, J.G., Schmitz, K., Ogg, G., 2012. The Geologic Time Scale 2012. Elsevier, volume 2, 1144 p.

Grant, S.F., Coe, A.L., Armstrong, H.A., 1999. Sequence stratigraphy of the Coniacian succession of the Anglo-Paris Basin. Geol. Mag. 136, 17-38.

Haq, U.B., Hardenbol, J., Vail, P.R., 1987. Chronology of fluctuating sea levels since the Triassic. Science 235, 11561167.

Hardenbol, J., Thierry, J., Farley, M.B., Jacquin, T., de Graciansky, P.C., Vail, P.R., 1998. Mesozoic and Cenozoic sequence chronostratigraphic framework of European basins: in de Graciansky, P.C., Hardenbol, J., Jacquin, t., and Vail, P.R., eds., Mesozoic and Cenozoic Sequence Stratigraphy of European Basins: Tulsa, OK, SEPM Special Publication 60, p. 3-13.

Hermoso, M., Le Callonnec, L., Minoletti, F., Renard, M., Hesselbo, S.P., 2009a. Expression of the Early Toarcian carbon-isotope negative excursion in separated microfractions (Jurassic, Paris Basin). Earth Planetary Science Letters 277, 194- 203. 
Hermoso, M., Minoletti, F., Le Callonnec, L., Jenkyns, H.C., Hesselbo, S.P., Rickaby, R.E.M., Renard, M., de Rafélis, M., Emmanuel, L., 2009b. Global and local forcing of Early Toarcian seawater chemistry: A comparative study of different paleoceanographic settings (Paris and Lusitanian basins). Paleoceanography 24, PA4208, doi:10.1029/2009PA001764.

Hermoso, M., Minoletti, F., Rickaby, R.E.M., Hesselbo, S.P., Baudin, F., Jenkyns, H.C., 2012. Dynamics of a stepped carbon-isotope excursion: Ultra high-resolution study of Early Toarcian environmental change. Earth and Planetary Science Letters 319-320, 45-54.

Hesselbo, S.P., Gröcke, D.R., Jenkyns, H.C., Bjerrum, C.J., Farrimond, P., Morgans Bell, H.S., Green, O.R., 2000. Massive dissociation of gas hydrate during a Jurassic oceanic anoxic event. Nature 406, 392-395.

Hesselbo, S.P., Jenkyns, H.C., 1995. A comparison of the Hettangian to Bajocian succession of Dorset and Yokshire, in Taylor, P.D., eds., Field Geology of the British Jurassic. Geological Society, London, p. 105-150.

Hesselbo, S.P., Jenkyns, H.C., 1998. British Lower Jurassic sequence stratigraphy. In: de Graciansky, P.-C., Hardenbol, J., Jacquin, Th., Vail, P.R. (Eds.), Mesozoic-Cenozoic Sequence Stratigraphy of European Basins. SPEM Special Publication 60, pp. 562-581.

Hesselbo, S.P., Jenkyns, H.C., Duarte, L.V., Oliveira, L.C.V., 2007. Carbon-isotope record of the Early Jurassic (Toarcian) Oceanic Anoxic Event from fossil wood and marine carbonate (Lusitanian Basin, Portugal). Earth and Planetary Science Letters 253, 455-470.

Hesselbo, S.P., Pienkowski, G., 2011. Stepwise atmospheric carbon-isotope excursion during the Toarcian Oceanic Anoxic Event (Early Jurassic, Polish Basin). Earth and Planetary Science Letters 301, 365-372.

Hinnov, L.A., 2000. New perspectives on orbitally forced stratigraphy. Annual Review of Earth and Planetary Sciences 28, 419-475.

Hinnov, L.A., Park, J.J., 1999. Strategies for assessing Early-Middle (Pliensbachian-Aalenian) Jurassic cyclochronologies. Philosophical Transactions of the Royal Society [London] A, 357, 1831-1859.

Howarth, M.K., 1992. The ammonite family Hildoceratidae in the Lower Jurassic of Britain. Paleontographical Society Monograph 586-590, $200 \mathrm{p}$.

Huang, C., Hesselbo, and S.P., Hinnov, L.A., 2010a. Astrochronology of the late Jurassic Kimmeridge Clay (Dorset, England) and implications for Earth system processes. Earth and Planetary Science Letters 289, $242-255$.

Huang, C., Hinnov, L.A., Fischer, A.G., Grippo, A., Herbert, T., 2010b. Astronomical tuning of the Aptian Stage from Italian reference sections. Geology 38, 899-902.

Huang, C., Hinnov, L.A., Ogg, J.G., Galbrun, B., Boulila, S., Huret, E., 2010. Astronomical calibration of the Jurassic time scale. Earth Science Frontiers 17, 108-109.

Huybers, P., Wunsch, C., 2003. Rectification and precession signals in the climate system. Geophysical Research Letters 30 (19), doi:10.1029/2003GL017875.

Ikeda, M., Tada, R., Sakuma, H., 2010. Astronomical cycle origin of bedded chert; middle Triassic bedded chert sequence, Inuyama, Japan. Earth and Planetary Science Letters 297, 369-378.

Imbrie, J., Hays, J.D., Martinson, D.G., Mclntyre, A., Mix, A.C., Morely, J.J., Pisias, N.G., Prell, W.L., and Shackleton, N.G., 1984, The orbital theory of Pleistocene climate: support from a revised chronology of the marine $\delta 180$ record, in Berger, A.L., Imbrie, J., Hays, J.D., Kukla, G., and Saltzman, B., eds., Milankovitch and climate, Part 1 : Reidel Publishing Group, Dordrecht, p. 269-305.

Karner, G.D., Driscoll, N.W., Weissel, J.K., 1993. Response of the lithosphere to in-plane force variations. Earth Planet. Sci. Lett. 114, 397-416.

Kemp, D.B., Coe, A.L., Cohen, A.S., Schwark, L., 2005. Astronomical pacing of methane release in the Early Jurassic period. Nature 437, 396-399.

Kemp, D.B., Coe, A.L., Cohen, A.S.,cWeedon, G.P., 2011. Astronomical forcing and chronology of the early Toarcian (Early Jurassic) Oceanic Anoxic Event in Yorkshire, UK. Paleoceanography 26, PA4210. doi:10.1029/2011PA002122.

Kominz, M.A., Miller, K.G., Browning, J.V., 1998. Long-term and short-term global sea-level estimates. Geology 26, 311-314.

Laskar J., 1990. The chaotic motion of the Solar System: A numerical estimate of the size of the chaotic zone. Icarus 88, 266-291.

Laskar J., Fienga A., Gastineau M., Manche H., 2011. La2010: A new orbital solution for the long term motion of the Earth. Astron. Astrophys. 532, A89, doi: 10.1051/0004-6361/201116836.

Laskar, J., Robutel, P., Joutel, F., Gastineau, M., Correia, A. C. M., Levrard, B., 2004. A long-term numerical solution for the insolution quantities of the Earth. Astronomy and Astrophysics 428, 261-285.

Laepple, T., Lohmann, G., 2009. Seasonal cycle as template for climate variability on astronomical timescales. Paleoceanography 24, doi: 10.1029/2008PA001674.

Littler, K., Hesselbo, S.P., Jenkyns, H.C., 2010. A carbon-isotope perturbation at the Pliensbachian-Toarcian boundary: evidence from the Lias Group, NE England. Geol. Mag., 147, 181-192. doi:10.1017/S0016756809990458. 
Lorenz, J., Lefavrais, A., Depeche, F., Leclerc, V., Marchand, D., Roy, B., Taugourdeau, J., and Reyre Y., 1987, Le Jurassique, in Lorenz, C., ed., Forage scientifique de Sancerre-Couy (Cher): Documents du Bureau de Recherches Géologiques et Minières 136, 19-26.

Lorenz, C., Lefavrais, A., Lorenz, J., Marchand, D., Million, R., 1991, Calage stratigraphique des diagraphies du Jurassique du sud du bassin Parisien à partir du sondage de Sancerre-Couy (Programme Géologie profonde de la France). Bulletin de la Société Géologique de France 162, 947-952.

Lourens, L.J., Hilgen, F.J., 1997. Long-periodic variations in the earth's obliquity and their relation to third-order eustatic cycles and Late Neogene glaciations. Quat. Int. 40, 43-52.

Lovell, B., 2010. A pulse in the planet: regional control of high-frequency changes in relative sea level by mantle convection. Journal of the Geological Society, London 167, 637-648.

Mann, M.E., Lees, J.M., 1996. Robust estimation of background noise and signal detection in climatic time series. Clim. Change 33, 409-445.

Matthews, R.K., Frohlich, C., 2002. Maximum flooding surfaces and sequence boundaries: comparisons between observations and orbital forcing in the Cretaceous and Jurassic (65-190 Ma). GeoArabia 7, 503-538.

Mattioli, E., Pittet, B., Suan, G., Mailliot, S., 2008, Calcareous nannoplankton changes across the early Toarcian oceanic anoxic event in the western Tethys. Paleoceanography 23, PA3208. doi:10.1029/2007PA001435.

Mazzini, A., Svensen, H., Leanza, H.A., Corfu, F., Planke, S., 2010. Early Jurassic shale chemostratigraphy and U-Pb ages from the Neuquén Basin (Argentina): Implications for the Toarcian Oceanic Anoxic Event. Earth and Planetary Science Letters 297, 633-645.

McArthur, J.M., Algeo, T.J., van de Schootbrugge, B., Li, Q., Howarth, R.J., 2008. Basinal restriction, black shales, ReOs dating, and the Early Toarcian (Jurassic) oceanic anoxic event. Paleoceanography 23, PA4217. doi:10.1029/2008PA001607.

McArthur, J.M., Donovan, D.T., Thirlwall, M.F., Fouke, B.W., Mattey, D., 2000, Strontium isotope profile of the early Toarcian (Jurassic) oceanic anoxic event, the duration of ammonite biozones, and belemnite palaeotemperatures. Earth and Planetary Science Letters 179, 269-285.

McElwain, J.C., Wade-Murphy, J., Hesselbo, S.P., 2005, Changes in carbon dioxide during an anoxic event linked to intrusion of Gondwana coals. Nature 435, 479-482.

Miall, A.D., 1990. Principles of Sedimentary Basin Analysis. Springer, Berlin, $2^{\text {nd }}$ edition.

Miller, K.G., Kominz, M.A., Browning, J.V., Wright, J.D., Mountain, G.S., Katz, M.E., Sugarman, P.J., Cramer, B.S., Christie-Blick, N., Pekar, S.F., 2005a. The Phanerozoic record of global sea-level change. Science 310, 1293-1298.

Ogg, J., Hinnov, L.A., 2012. Chapter 26: The Jurassic Period, in Gradstein, F., Ogg, J., Ogg, G., and Smith, D., eds., A Geologic Time Scale 2012, Elsevier, 731-791.

Olsen, P.E., Kent, D.V., 1999, Long-periof Milankovitch cycles from the Late Triassic and Early Jurassic of eastern North America and their implications for the calibration of the Early Mesozoic time-scale and the long-term behavior of the planets. Philosophical Transactions of the Royal Society [London] A, 357, 1761-1788.

Pálfy, J., Smith, P.L., Mortensen, J.K., 2000. A U-Pb and ${ }^{40} \mathrm{Ar} /{ }^{39} \mathrm{Ar}$ time scale for the Jurassic. Canadian Journal of Earth Sciences 37, 923-944.

Rey, J., Cubaynes, R., 1991. Séquences lithoclinales et séquences génétiques de dépôt dans le Lias moyen du Bassin aquitain. Comptes Rendus de l'Académie des Siences 312, II, 1447-1463.

Sloss, L.L., 1963. Sequences in the cratonic interior of North America. Geol. Soc. Am. Bull. 74, 93-114.

Strasser, A., Hillgärtner, H., Hug, W., Pittet, B., 2000. Third-order depositional sequences reflecting Milankovitch cyclicity. Terra Nova 12, 303-311.

Suan, G., Pittet, B., Bour, I., Mattioli, E., Duarte, L.V., Mailliot, S., 2008, Duration of the Early Toarcian carbon isotope excursion deduced from spectral analysis: consequence for its possible causes: Earth Planetary Science Letters 267, 666-679.

Taner, M.T., 2000, Attributes Revisited, Technical Publication. Rock Solid Images, Inc., Houston, Texas. URL: http://www.rocksolidimages.com/pdf/attrib_revisited.htm.

Thomson, D.J., 1982, Spectrum estimation and harmonic analysis: Proceedings of the IEEE 70, 1055-1096.

Vail, P.R., Audemard, F., Bowman, S.A., Eisner, P.N., Perez-Cruz, C., 1991. The stratigraphic signatures of tectonics, eustasy and sedimentology - an overview. In: Einsele, G. et al. (Eds.), Cycles and Events in Stratigraphy, pp. 617659. Springer, Berlin.

Vail, P.R., Mitchum, R.M., Todd, J.R.G., Widmier, J.M., Thompson, S., Sangree, J.B., Bubb, J.N., Hatlelid, W.G., 1977. Seismic stratigraphy and global changes of sea level. In: Payton, C.E. (Eds.), Seismic Stratigraphy - Applications to Hydrocarbon Exploration. Mem. Am. Ass. Petrol. Geol. 26, pp. 49-212.

Weedon, G., 2003. Time-Series Analysis and Cyclostratigraphy - Examining Stratigraphic Records of Environmental Cycles, Cambridge University Press, $260 \mathrm{pp}$.

Wignall, P.B., Newton, R.J., Little, C.T.S., 2005, The timing of paleoenvironmental change and cause-and-effect 
relationships during the Early Jurassic mass extinction in Europe. American Journal of Sciences 305, 1014-1032. 


\section{SUPPLEMENTARY INFORMATION}

\section{A. Details on ammonite biostratigraphy}

The Sancerre core bears abundant invertebrate macrofauna, especially ammonites (around 100 specimens) but also some bivalves and belemnites. Although fossils are often preserved as impression or moulds; many shell characters are well preserved, enabling determination at the species level for $40 \%$ of the specimens. When some characteristics appeared unclear, because of compression of the specimen, we used the sign "gr." for the identification. This means that the specimen could not be assigned to a particular species but to a group of species, generally closely related, and is relevant for biostratigraphic study.

The fauna are typical of the Toarcian NW European ammonite assemblage composed of Dactylioceratidae and Hildoceratidae. The biostratigraphic framework established in this study is based on standard NW European ammonite zonations (Elmi et al. 1994; 1997; see Howarth, 1992 for correlation with England and Macchioni, 2002 for Mediterranean areas).

Tenuicostatum Zone:

Depth $352.8 \mathrm{~m}$ to $351 \mathrm{~m}$ : occurrence of Dactylioceras (Orthodactylites) at $352.8 \mathrm{~m}, 351.1 \mathrm{~m}$ and $351 \mathrm{~m}$. Specific determination of Dactylioceras is very delicate on compressed material. The costulation and the coiling associated with the type of rib bifurcation assign these specimens to the typical early $D$. (O.) gr. tenuicostatum - semicelatum of the early Toarcian, Tenuicostatum Zone (Plate S1, photos 11 and 12).

Serpentinum Zone:

Depth $348 \mathrm{~m}$ to $321.85 \mathrm{~m}$ : characterized by a rich fauna of Harpoceratinae (15 specimens) with $H$. gr. serpentinum - falciferum (Plate S1, photo 10), Eleganticeras sp., Harpoceras sp., Cleviceras exaratum?. Late $D$. (O.), typical of the Serpentinum Zone also occur as D. (O.) semiannulanum? (Plate S1, photos 7 and 8).

\section{Bifrons Zone:}

Depth $321.45 \mathrm{~m}$ to $279.35 \mathrm{~m}$ : first occurrence of the genus Hildoceras. The succession of Hildoceras species with $H$. sublevisoni, $H$. lusitanicum, $H$. bifrons is found at these levels (Plate S1, photos 5, 6 and 9). At the top, a specimen of $H$. semipolitum (Plate S1, photo 4) indicates that the last horizon of the Bifrons Zone is reached. In this interval Hildoceras are associated with Harpoceratinae belonging to the last Harpoceras and Pseudolioceras and with Dactylioceras s. st. 
Aalensis Zone:

Depth $206.2 \mathrm{~m}$ to $198.5 \mathrm{~m}$ : first occurrence of Pleydellia with forms close to the last Dumorteria as $P$. gr. mactra (206.2 m and 204.4 m), (Plate S1, photo 3), Pleydellia sp. (204.3 m). A specimen of Pleydellia aalensis occurs at $201.4 \mathrm{~m}$ (Plate $\mathrm{S} 1$, photo 2). A more involute form with a marked umbilical edge as $P$. (Walkericeras) lugdunensis? occurs at $201.9 \mathrm{~m}$, (Plate S1, photo 1). Pleydellia sp. (198.05 m) is incomplete, the rib density and shape seem close to $P$. steinmanni. At $195.55 \mathrm{~m}$, a large specimen (shell diameter $>6 \mathrm{~cm}$ ) occurs, sub-involute exhibiting sinuous, weak to striate ribs. This form corresponds to the transition between the last $P$. buckmanni and the first Leioceras of the Aalenian.

) 


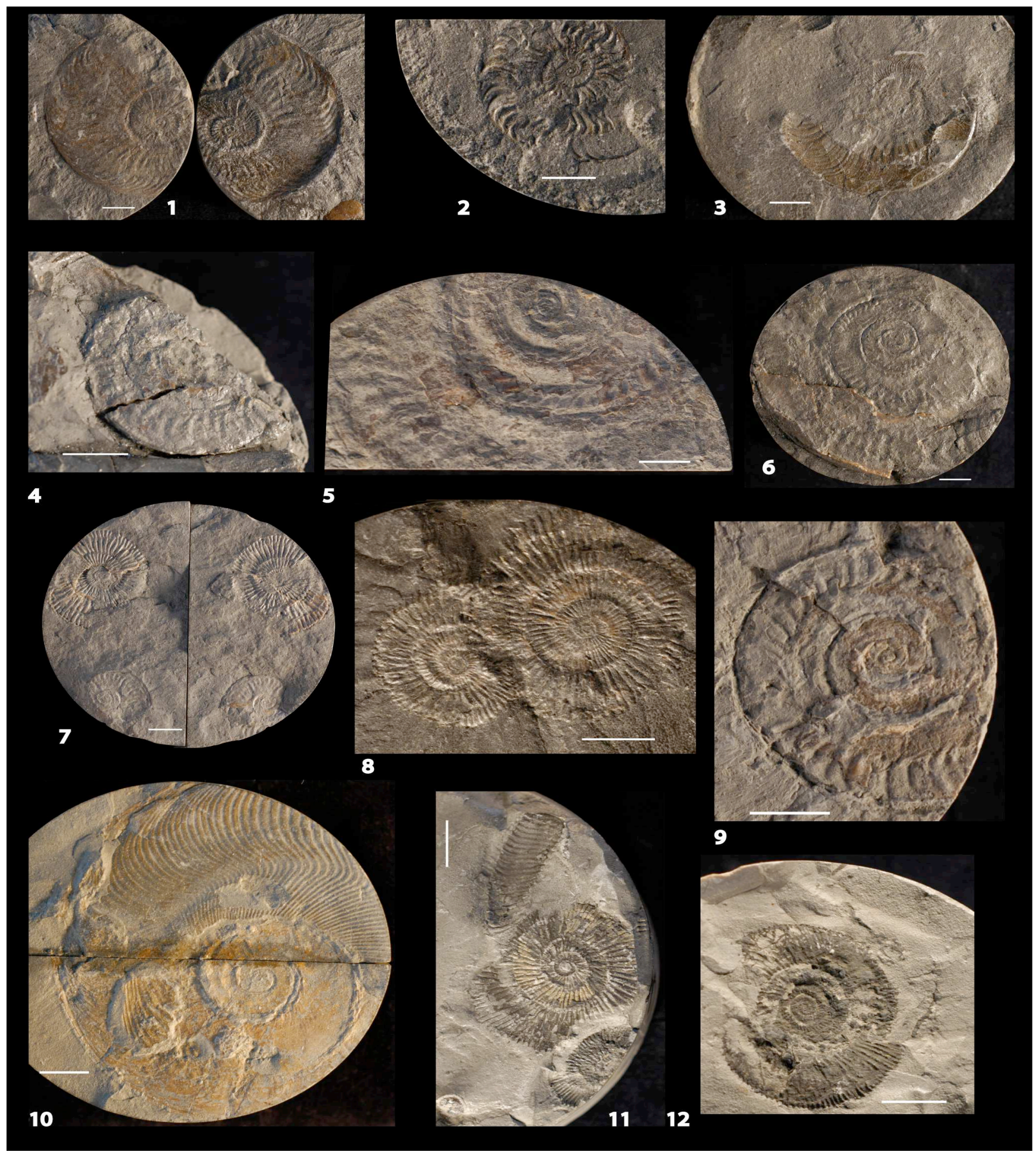

Suppl. Plate S1 : (1) Pleydellia (Walkericeras) lugdunensis? (199.8 m). (2) P. (Pleydellia) aalensis (201.9 m). (3) P. (P.) gr. mactra (204.4 m). (4) Hildoceras semipolitum (280 m). (5) H. bifrons (316.05 m). (6) H. lusitanicum $(317.7 \mathrm{~m})$. (7) Mould and imprint of the same specimen, Dactylioceras (Orthodactylites) gr. semiannulatum (325.6 m), below Harpoceratinae, Cleviceras exaratum? (325.6 m). (8) D. (O.) gr. semiannulatum (329.9 m). (9) H. gr. sublevisoni-lusitanicum (321.45 m). (10) Harpoceras gr. serpentinum - falciferum (333.3 m). (11) and (12) D. (O.) gr. tenuicostatum - semicelatum (351 m and $352.10 \mathrm{~m})$. 


\section{B. Details on nannofossil biostratigraphy}

The abundant and diverse calcareous nannofossil assemblages recovered along the Sancerre core show a mixed Boreal/Tethyan composition (Plate S2). Several first and last occurrences of nannofossil species are found along the studied section; this local succession of biohorizons is comparable with that of the NW Europe basins and Northern Tethyan margin. In this study we adopted the nannofossil zonation proposed by Bown and Cooper (1998) as well as the calcareous nannofossil biostratigraphic synthesis by de Kaenel et al (1995).

The presence of Crepidolithus impontus (C. cavus of some authors) from the lowest studied sample (357.20 m) indicates part of NJ5b, a subzone that spans the uppermost Pliensbachian (Spinatum Zone) to lower Toarcian (Falciferum Zone) (Bown and Cooper, 1998). The LO of Crucirhabdus primulus, a horizon which is reported from the base (Bown and Cooper, 1988) or within (de Kaenel et al., 1995) the Tenuicostatum Zone, is observed at $349 \mathrm{~m}$. Mitrolithus jansae disappears at $348.68 \mathrm{~m}$. This horizon is reported to occur at the base of Serpentinum Zone in the majority of studied sections and may be a good correlative event (Bown and Cooper, 1998; de Kaenel et al., 1995). The following horizons are also associated to the Serpentinum Zone although the order of events can vary among different regions: the LO of Similiscutum finchii (large morphotypes) at $347.76 \mathrm{~m}$, the FO of Carinolithus superbus at $347 \mathrm{~m}$, the LO of Biscutum grande at $344 \mathrm{~m}$ and the LO of Parhabdolithus liasicus distinctus at $343 \mathrm{~m}$. Rarest Carinolithus superbus are first observed at at $347.76 \mathrm{~m}$ allowing the distinction between NJ5b subzone and NJ6 Zone (Bown and Cooper, 1998). This taxon, however, is always very rare in the Serpentinum Zone and it will become consistent only in the Bifrons Zone.

From $336 \mathrm{~m}$ to the top, calcareous nannofossil assemblages are very reduced in abundance making the search for key species more difficult. Nonetheless, the FO of Discorhabdus striatus at $331 \mathrm{~m}$ marks the long NJ7 Zone, which spans the top of Falciferum to Levesquei zones (Bown and Cooper, 1998). The FO of $D$. criotus recorded at $298 \mathrm{~m}$ is a useful horizon that can help to subdivide the NJ7 Zone and it is usually observed from the top of Bifrons to Variabilis zones (Bown and Cooper, 1998; de Kaenel et al., 1995). Very rare Biscutum depravatum and B. intermedium are observed at $238 \mathrm{~m}$ and $221.45 \mathrm{~m}$ respectively. Acknowledged to occur in the upper Toarcian (Thouarsense to Insigne zones), these events are still poorly calibrated with ammonite zones, and their appearance order needs to be better calibrated (de Kaenel et al., 1995). No Retacapsa incompta, marker of the upper Toarcian NJ8 Zone (Levesquei to Laeviuscula zones), was encountered in this study, but the FO of $B$. intermedium is proposed by Bown and Cooper (1998) as a proxy for the base of this zone. The FO of Triscutum spp. is also used to approximate the NJ8 Zone; this taxon is observed from $210.50 \mathrm{~m}$. 
CALCAREOUS NANNOFOSSILS - Polarising microscope, scale bar $5 \mu \mathrm{m}$

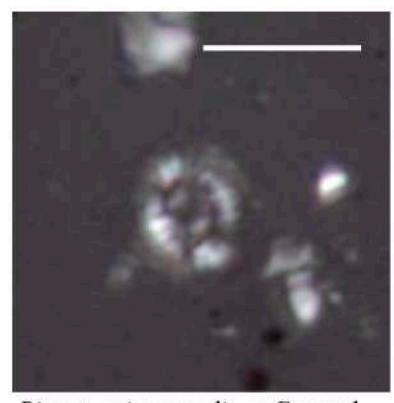

Biscutum intermedium. Crossed nicols. Sample 231

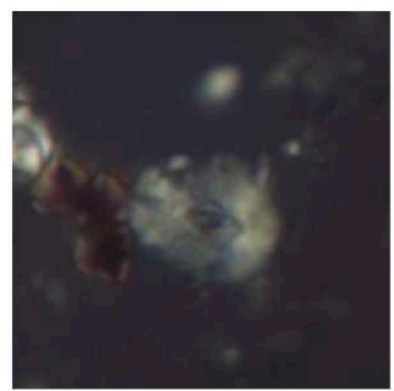

Biscutum finchii. Crossed nicols.

Sample 348.

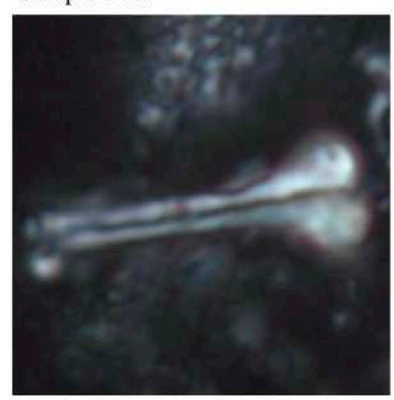

Carinolithus superbus. Crossed nicols. Sample 305.

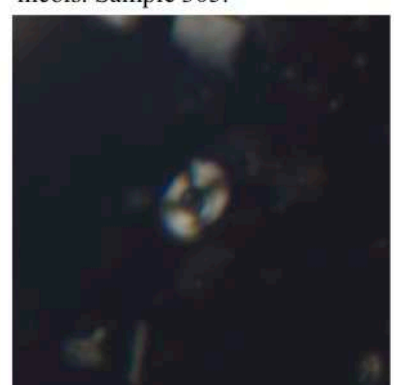

Lotharingius hauffii. Crossed nicols. Sample 331.

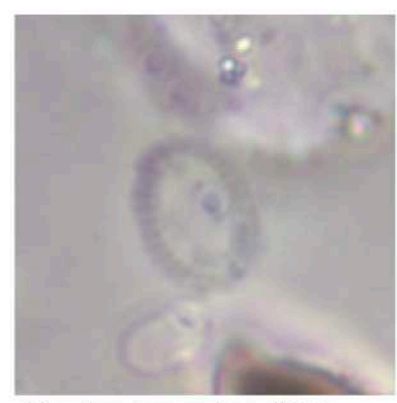

Biscutum depravatum. Phase contrast. Sample 238

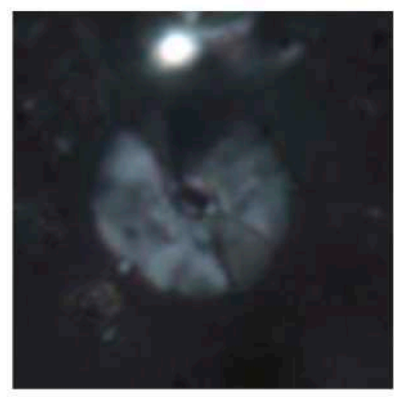

Discorhabdus criotus. Crossed nicols. Sample 241.

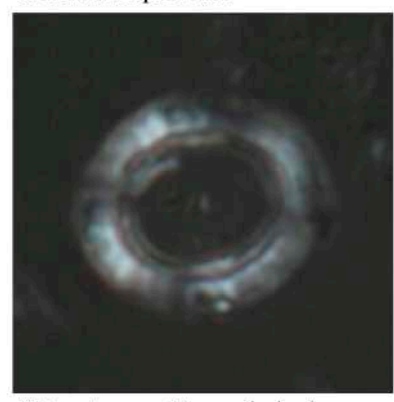

Triscutum sp. Crossed nicols. Sample 208,35.

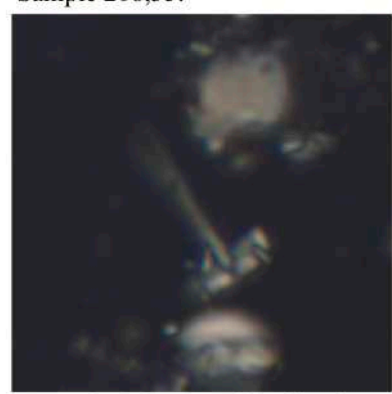

Crucirhabdus primulus side view. Crossed nicols. Sample 352.

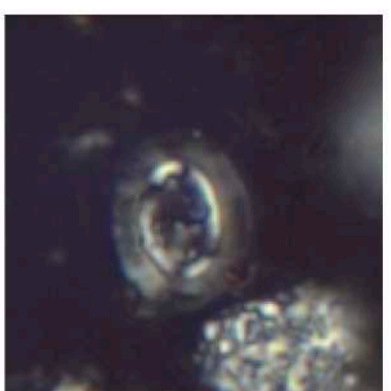

Biscutum grande. Crossed nicols. Sample 348.

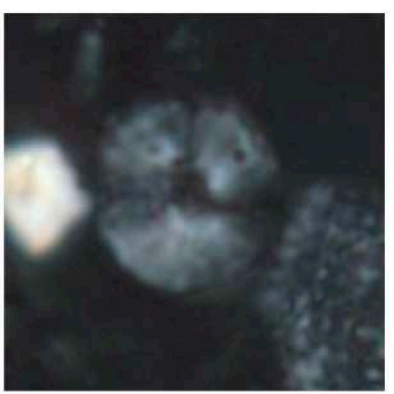

Discorhabdus striatus. Crossed nicols. Sample 290.

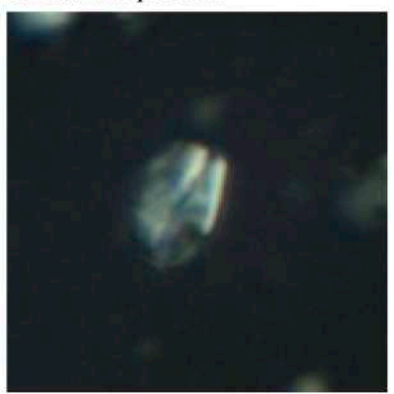

Calcivascularis jansae. Crossed nicols. Sample 357,07.

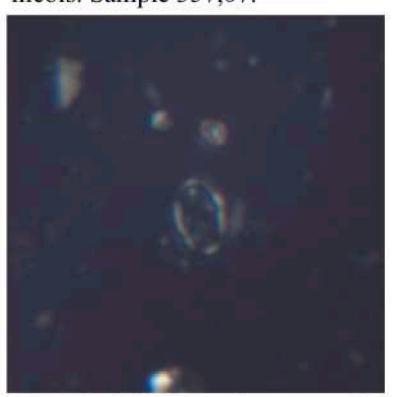

Crucirhabdus primulus. Crossed nicols. Sample 352.

\section{Suppl. Plate S2: Calcareous nannofossils.}




\section{Supplementary Figures}
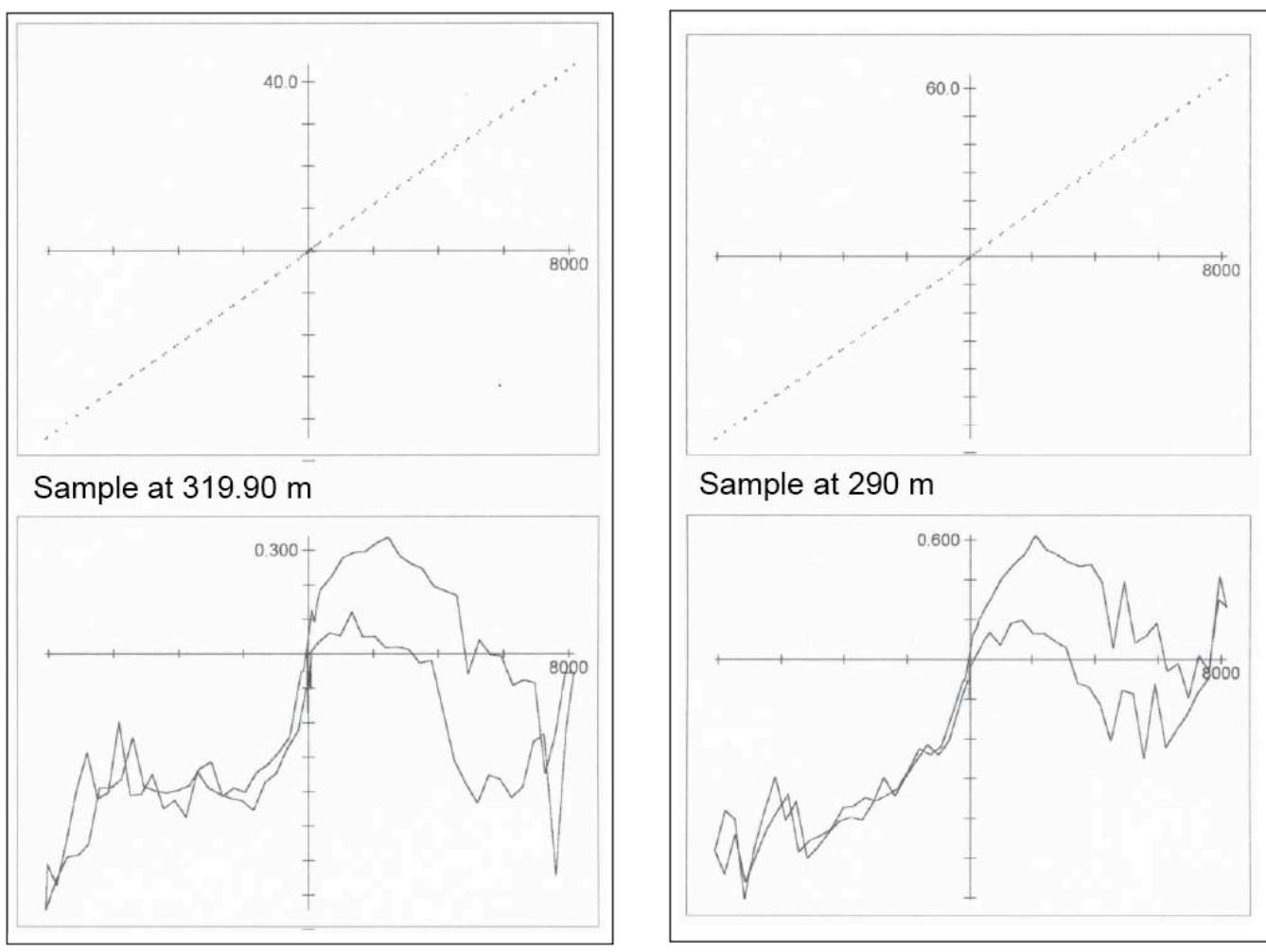

Sample at $290 \mathrm{~m}$
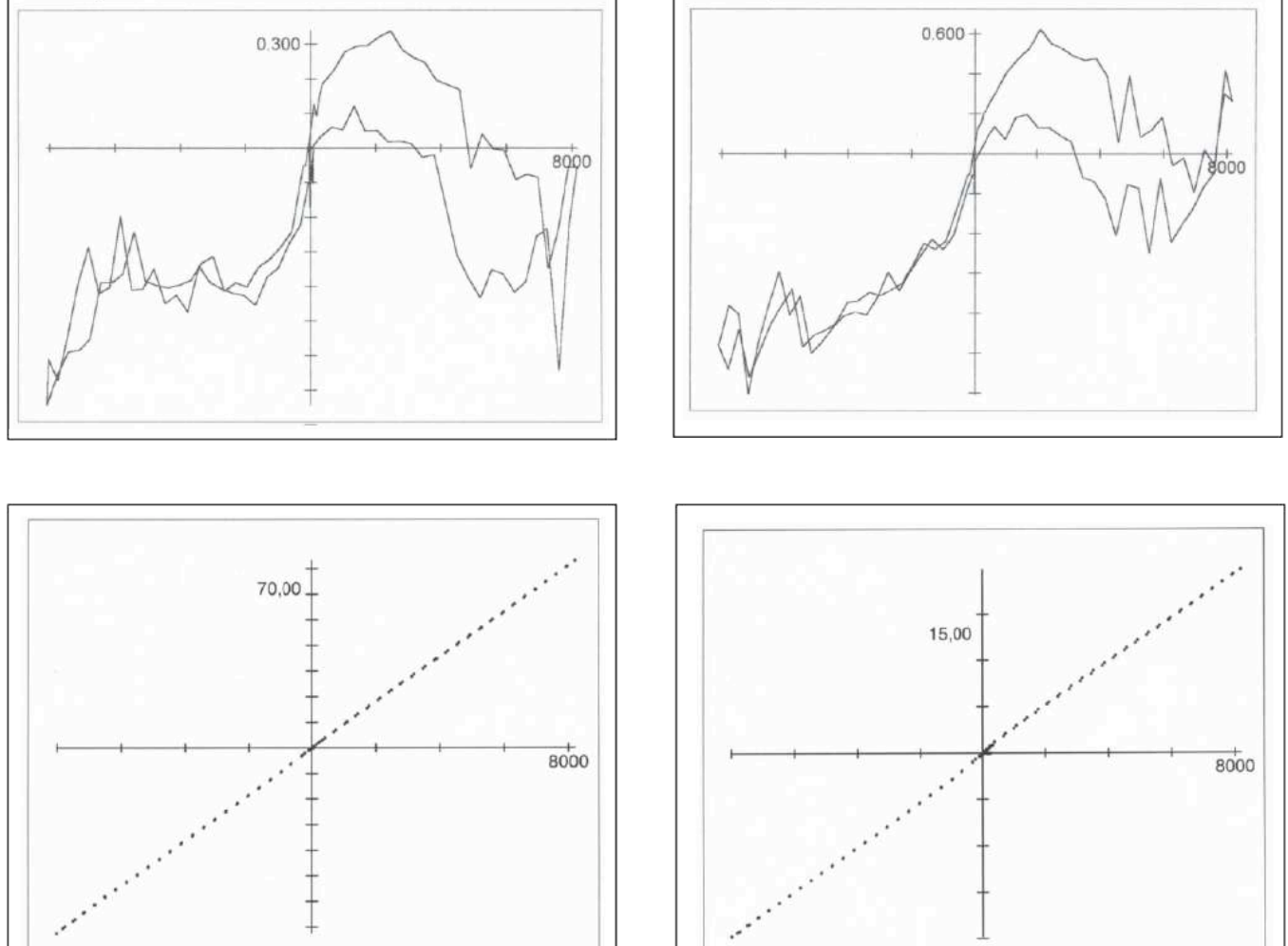

Sample at $264.7 \mathrm{~m}$

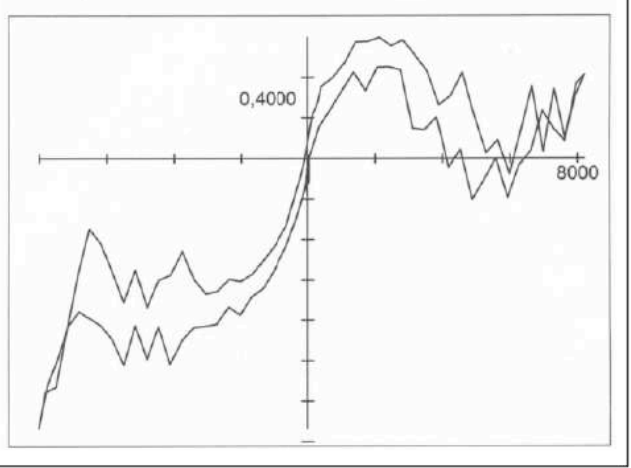

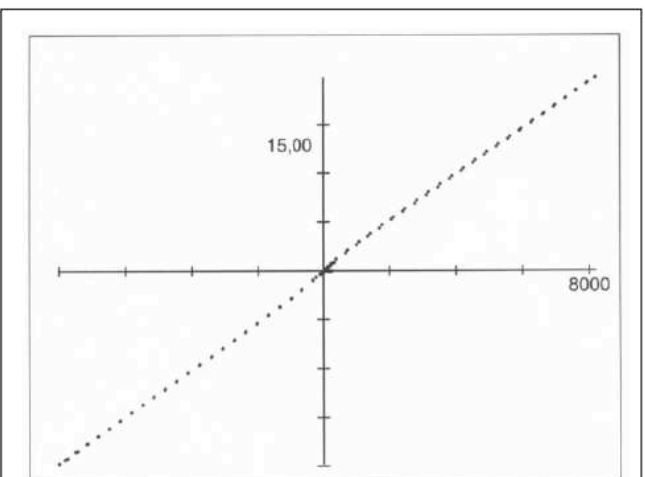

Sample at $195.02 \mathrm{~m}$

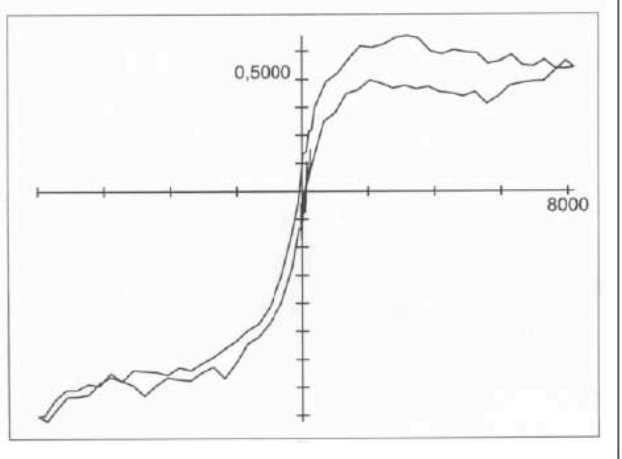

Figure S1: Hysteresis loop up to 0.8 T of well-spaced samples in the Sancerre core (depth positions of the measured samples are shown). Upper plot : raw results showing a strong paramagnetic signal caused by clay minerals, lower plot : results after subtracting the paramagnetic component showing no clear ferrimagnetic component. 

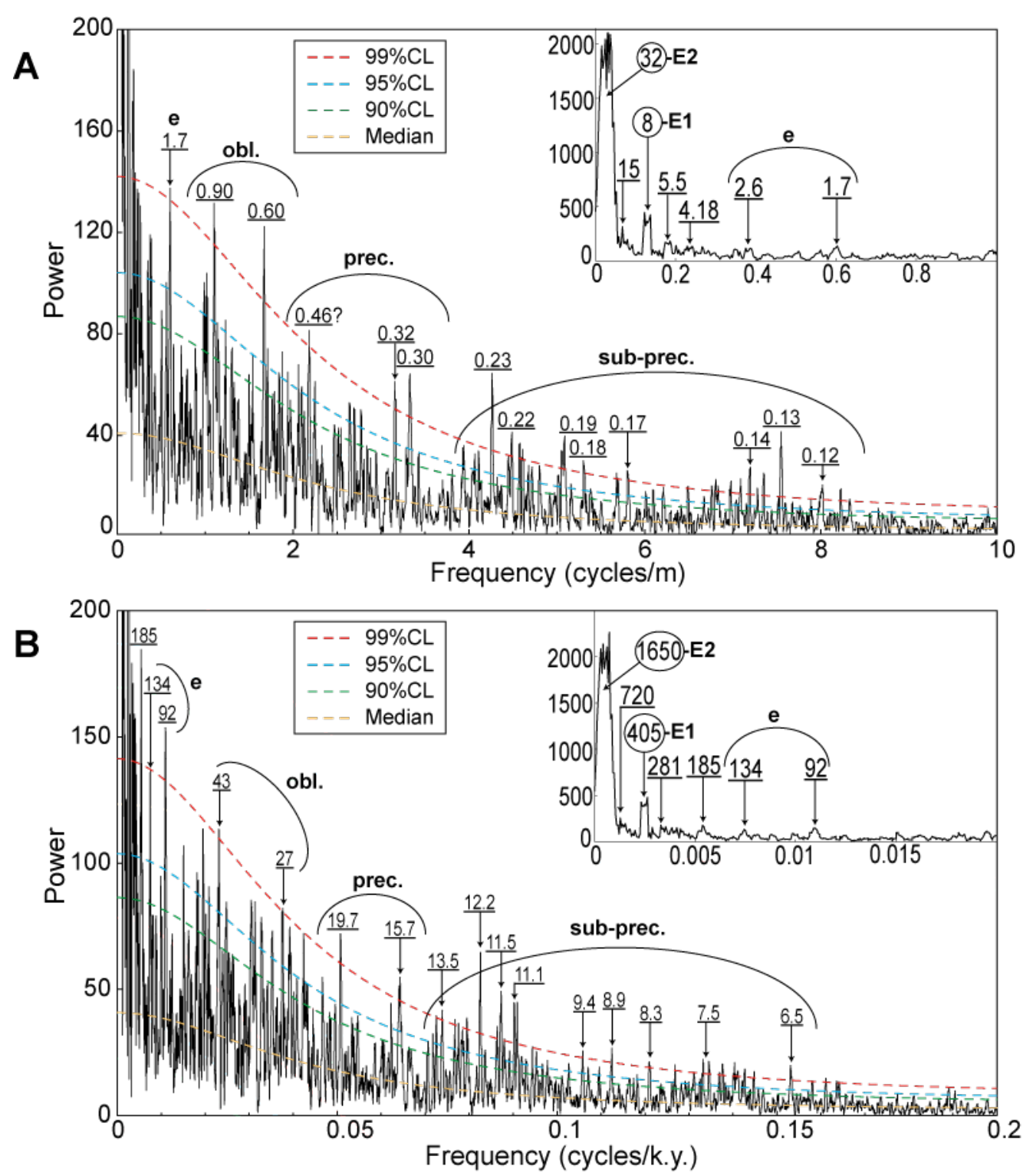

Figure S2: $2 \pi$ MTM spectra of the entire MS data series on a linear-scale over a frequency range around the half of Nyquist limit (x-axis), with a truncated power scale (y-axis). Noise models used linear fitting and median filtering over $20 \%$ of the Nyquist frequencies ([0,25 cycles/m] for the untuned series in 'A', and [0,0.5 cycles/kyr] for the tuned series in ' $B$ '). (A) Untuned spectrum with the two high-power ( 2000 and 400$)$ peaks at the lower frequencies (32- and 8-m wavelengths) truncated to emphasize the high-frequency portion of the spectrum. Most peaks exceeding $99 \% \mathrm{CL}$ are labelled (in meters). Inset: spectrum to show the low-frequency portion of the spectrum; wavelengths (32 and $8 \mathrm{~m}$ ) of the two strongest peaks are circled. (B) Tuned spectrum with, the two highpower ( 2000 and $\sim 400$ ) peaks at the lower frequencies (1650- and 450-kyr periods) truncated to emphasize the high-frequency portion of the spectrum. Most peaks exceeding $99 \% \mathrm{CL}$ are labelled (in kyr). Inset: spectrum over $[0,0.02 \mathrm{cycles} / \mathrm{kyr}]$ to show the low-frequency portion of the truncated spectrum, periods (1650 and $405 \mathrm{kyr}$ ) of the two strongest peaks are circled. Symbols: $g_{4}-g_{3}$ eccentricity term (E2), $g_{2}-g_{5}$ (405 kyr) eccentricity term (E1), short eccentricity ( 100 kyr) term (e), obliquity (Obl.), precession (prec.), sub-Milankovitch or sub-precession (sub-prec.). 

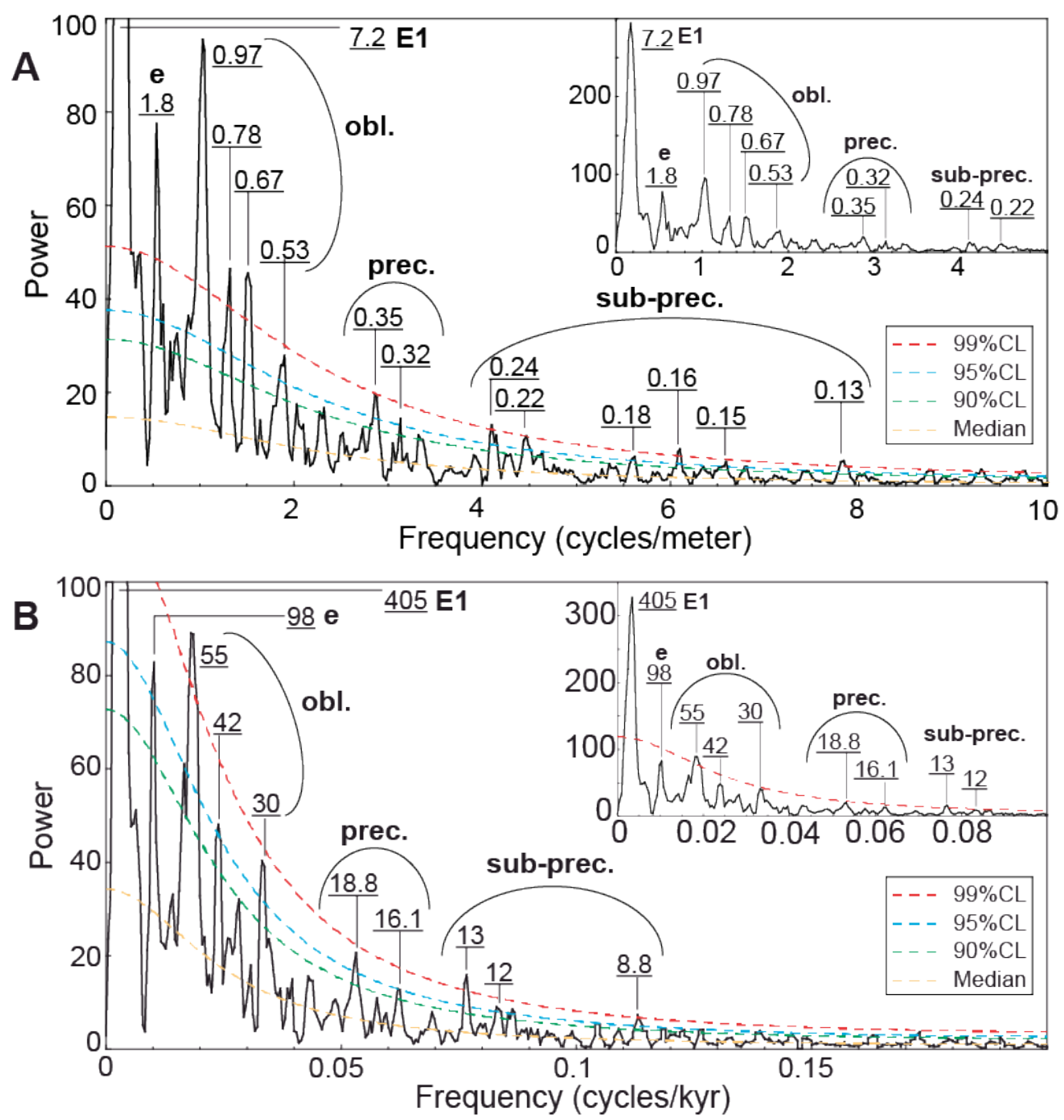

Figure S3: $2 \pi$ MTM power spectra of the interval $360 \mathrm{~m}$ to $325 \mathrm{~m}$ (interval in Fig. 3). Robust red noise models were computed linear fitting and median filtering over $20 \%$ of the Nyquist frequencies (12.5 cycles/m for the raw data in 'A', and 0.25 cycles/kyr for the tuned data in 'B'). (A) Untuned spectrum with the high-power $(\sim 300)$ peak at the lowest frequency $(7.2 \mathrm{~m})$ truncated to emphasize the high-frequency portion of the spectrum. Inset: spectrum over [0, 5 cycles $/ \mathrm{m}]$ to show the low-frequency portion of the truncated spectrum. (B) Tuned spectrum with the high-power ( 300) peak at the lowest frequency (405 kyr) truncated to emphasize the high-frequency portion of the spectrum. Inset: spectrum over [0, 0.1 cycles/kyr] to show the low-frequency portion of the spectrum. 

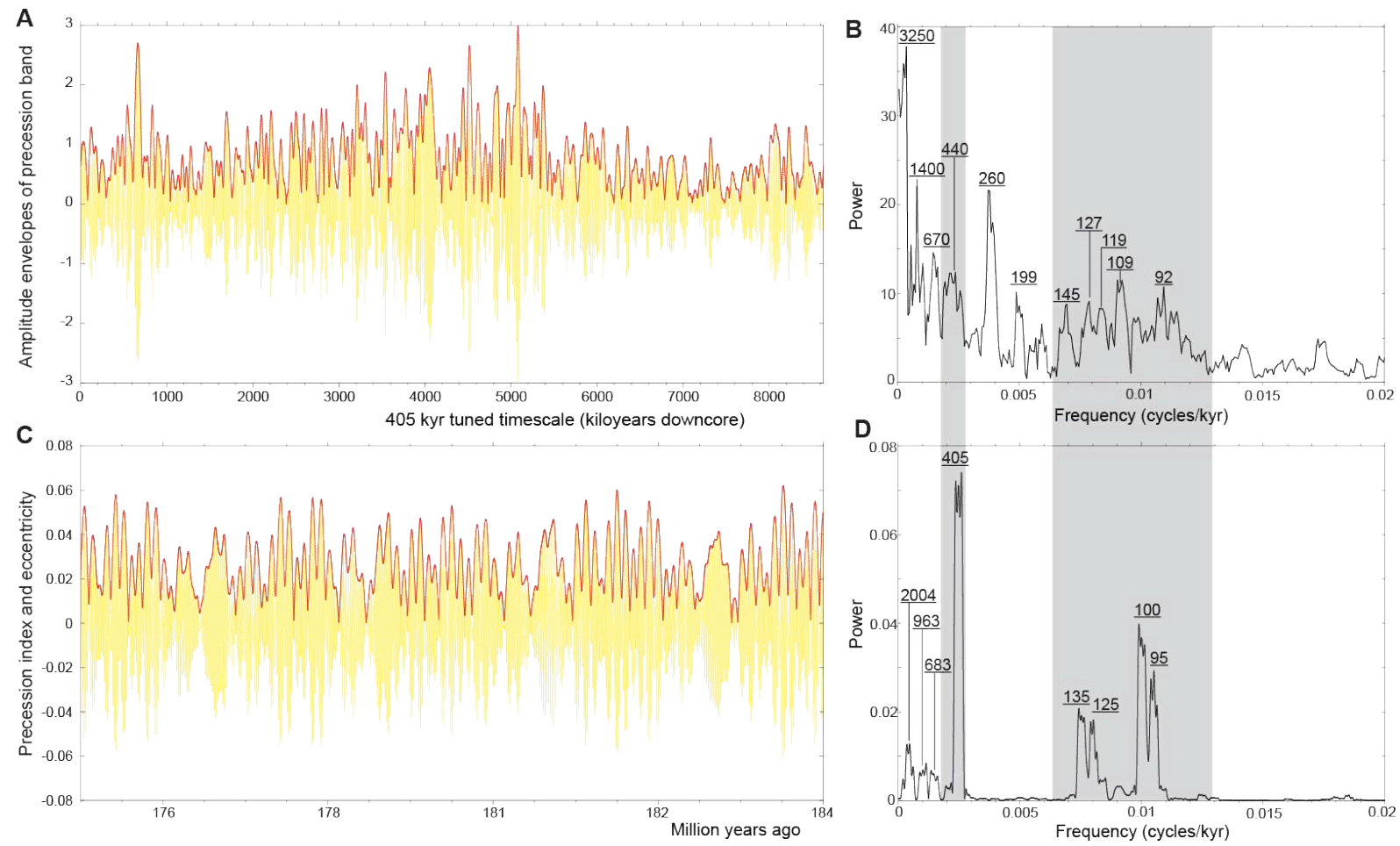

Figure S4: Amplitude modulation (AM) analysis of the MS variations at the precession cycle band, and comparison with the theoretical orbital eccentricity. (A) AM of the precession band (0.04 and 0.065 cycles/kyr passband cutoff frequencies) of the tuned MS series. (B) $2 \pi$ MTM power spectrum of envelopes in 'A'. (C) La2004 precession and eccentricity variations of Laskar et al. (2004). (D) $2 \pi$ MTM power spectrum of eccentricity variations in ' $C$ '. Grey-shaded areas represent precession modulations at the 100 and $400 \mathrm{kyr}$ cycle bands detected in MS series in 'B', and their astronomical equivalent periodicities in ' $D$ '. All spectral peak labels are in kyr. 

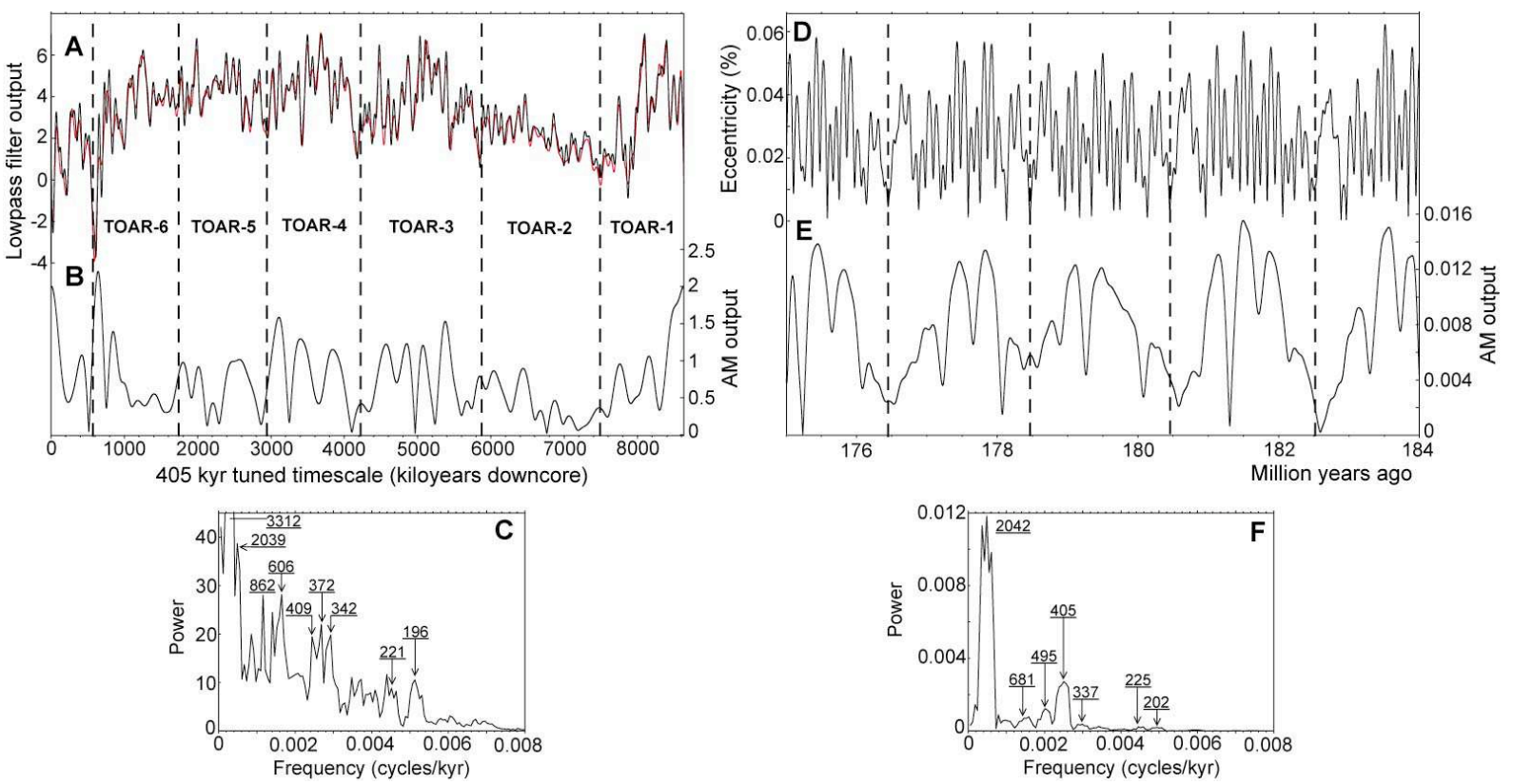

Figure S5: Amplitude modulation (AM) analysis of the MS variations at the eccentricity cycle band, and comparison with AM analysis of the theoretical orbital eccentricity. (A) Lowpass filtered MS tuned series isolates $100 \mathrm{kyr}$ eccentricity and longer periods as in Fig. 4B. (B) AM of the $100 \mathrm{kyr}$ eccentricity band (0.0071 and 0.014 cycles/kyr passband cutoff frequencies) of the 405-kyr tuned MS series. (C) $2 \pi$ MTM power spectrum of ' $B$ ', the high-power $(\sim 70)$ peak at the lowest frequency (3312 kyr) is truncated to emphasize the high-frequency portion of the spectrum. (D) Orbital eccentricity variations in the La2004 astronomical model (Laskar et al., 2004) for the interval 175 to $184 \mathrm{Ma}$. (E) AM of the $100 \mathrm{kyr}$ eccentricity band $(0.0071$ and 0.0161 cycles/kyr passband cutoff frequencies). (F) $2 \pi$ MTM power spectrum of 'E'. Vertical dashed lines in the MS series delimit the TOAR-1 to TOAR-6 cycles with a mean period of $\sim 1.6 \mathrm{Myr}$ (Fig. S2), interpreted as $\mathrm{g}_{4}-\mathrm{g}_{3}$ eccentricity cycles, that has a period of $\sim 2$ Myr in the La2004 model, also indicated by vertical dashed lines. All spectral peak labels are in kyr. 


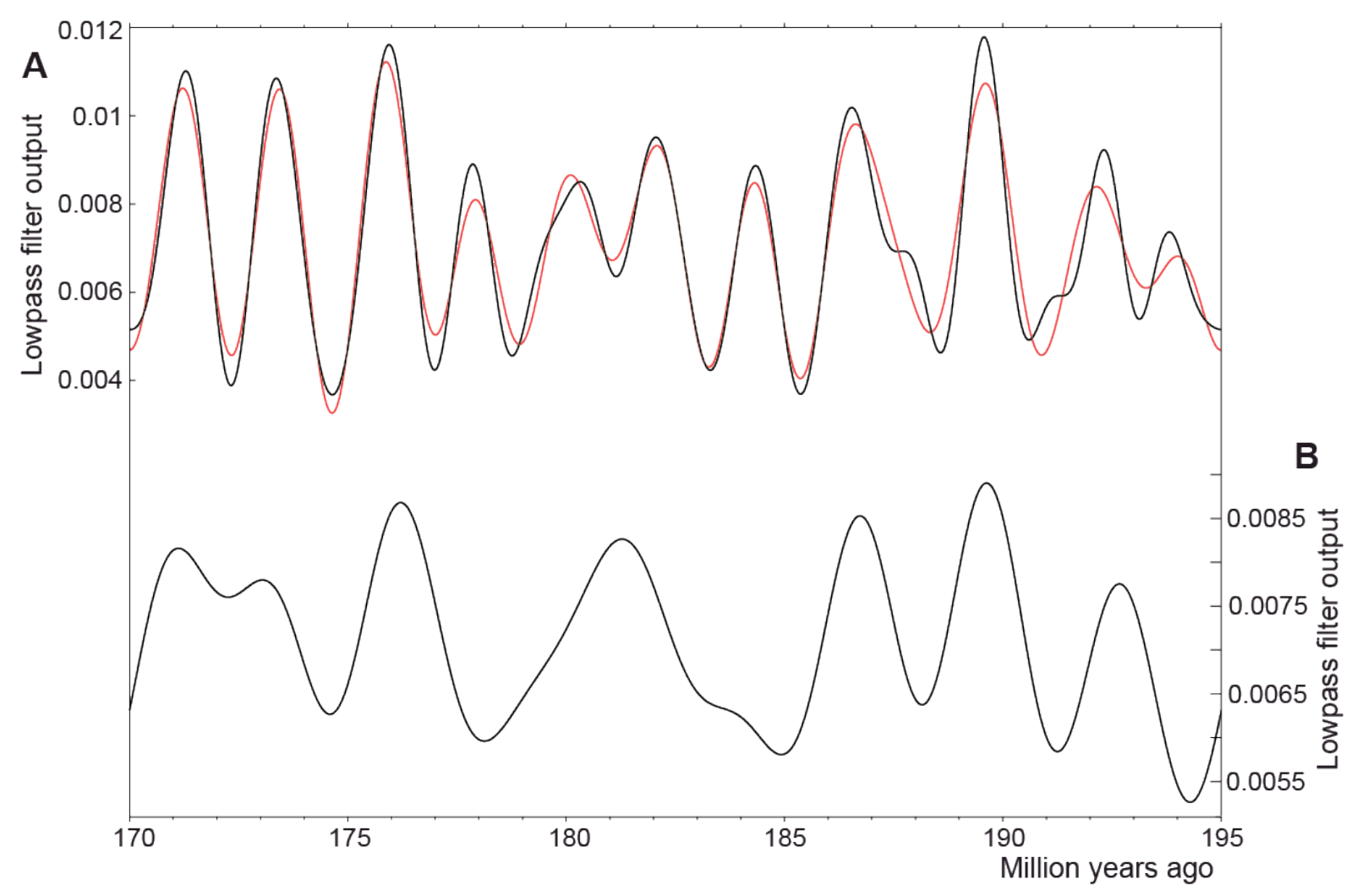

Figure S6: Low-pass filtering of the La2010d orbital eccentricity time series (Laskar et al., 2011) to extract $g_{4}-g_{3}$ related cyclicity, which is associated with resonant behavior between Earth and Mars (Laskar, 1990; Laskar et al., 1992), where $g_{3}$ and $g_{4}$ describe the precession of the perihelia of the orbits of Earth and Mars. (a) 2 Myr eccentricity cycles extracted with a moderate cut-off (0.6 cycles/Myr, red line) and a wide cut-off (0.8 cycles/Myr, black line). (b) $\sim 3.2$ Myr eccentricity cycles extracted with a 0.37 cycles/Myr cut-off frequency. All low-pass filtering was performed using the Taner filter (Taner, 2000). The $\sim 2$ and $\sim 3.2$ Myr eccentricity cycles correspond to the secular frequencies $g_{4}-g_{3}$ and $1 / 2\left(g_{4}-g_{3}\right)$ respectively (J. Laskar, pers. comm.). Their respective Cenozoic mean values are $\sim 2.4$ and $\sim 4.5 \mathrm{Myr}$. Shortening of these periods in the Mesozoic is explained by the chaotic motion of the inner planets (here between Mars and the Earth).

\section{Details on sequence stratigraphy}

Here we compare the biostratigraphic positions of TOAR cycles, when available, with those of third-order eustatic sequences, and we summarized the main sedimentological features in the French sequences as described in the reference chart of Hardenbol et al. (1998), who refer to Graciansky et al. (1998).

TOAR-1 Cycle: 
The TOAR-1 cycle includes PI8-Toa1 and Toa1-Toa2 sequences (Toa1 is a minor boundary, Table 2). The lower minimum of TOAR-1 cycle is not recovered in our MS record. It may correspond to PI8 sequence boundary in the Spinatum Zone of the upper Pliensbachian. The upper minimum of TOAR-1 is situated in the Serpentinum Zone similar to the Toa2 boundary. It is characterized by carbonate-rich and silty marls (Fig. 2). In the subsiding parts of the southeastern France Basin, it is expressed by a lithological change from homogenous marls to marls with nodular wackestones (Graciansky et al., 1993). In the Quercy basin, a sharp lithological change from organic-rich shales to marls was noted at Toa2 boundary (Rey and Cubaynes, 1991). Given the uncertainties in ammonite boundary assignement in Sancerre, the maximum of TOAR-1 could be placed either in the upper Spinatum or Tenuicostatum or the lower Serpentinum Zone. It likely corresponds to the maximum flooding surface (MFS) of Toa1-Toa2 sequence placed at the lower part of the Serpentinum Zone. This MS maximum is situated around the onset of CIE associated with the T-OAE (Fig. 2). In the eustatic chart, it is considered as a widespread 1st-order (and $2^{\text {nd }}$ order) MFS dated as lower part of the Bifrons Zone in the Tethyan areas, and as Falciferum Subzone within the U.K. organic-rich shales that constitute one of the major source rocks in western Europe (Jenkyns, 1984, 1988).

\section{TOAR-2 Cycle:}

The TOAR-2 cycle includes Toa2-Toa3 and Toa3-Toa4 sequences (Toa3 is a minor boundary, Table 2). The upper minimum of TOAR-2 cycle is situated at the middle part of the Bifrons Zone. It coincides with Toa4 sequence boundary (middle Bifrons Zone, base of Bifrons Subzone). It is an erosional surface in the Quercy basin, and it is amalgamated with the overlying Toar5 sequence boundary in southeastern France Basin. The maximum of TOAR-2 cycle is in the lowermost part of the Bifrons Zone, which may correspond to the maximum flooding surface of Toa2-Toa3 sequence at Serpentinum/Bifrons boundary.

\section{TOAR-3 Cycle:}

The TOAR-3 cycle corresponds to Toa4-Toa5 sequence. Its upper minimum could be either in the upper part of Bifrons Zone or in the lower part of Variabilis, because this latter is not recognized in Sancerre. It matches Toa4 sequence boundary, assigned to the Bifrons Zone in the Quercy basin. The maximum of TOAR-3 cycle is in the middle part of the Bifrons Zone, which may indicate the maximum flooding surface of Toa4-Toa5 sequence, though this latter is placed in the lower part of Variabilis Zone. Toa4-Toa5 sequence is well expressed in the Paris and Aquitaine basins, but is missing or extremely condensed in southeastern France Basin (Graciansky et al., 1993).

\section{TOAR-4 to TOAR-6 Cycles:}


Stratigraphic positions of the TOAR-4, TOAR-5 and TOAR- 6 cycles could not be compared in detail with their equivalent third-order sequences in the chart because of the lack of ammonite biostratigraphy in Sancerre. TOAR-4 cycle may correspond to Toa5-Toa6 sequence, which is particularly well expressed in the Penne section of Quercy basin (Cubaynes et al., 1990). However, TOAR-5 and TOAR-6 cycles may match only one third-order sequence Toa6-Toa7. The longer duration of Toa6-Toa7 sequence compared to the other Toarcian sequences leads us to consider that it may represent two sequences. According to GTS2004, the duration of Toa6-Toa7 sequence is estimated as 2.2 Myr, a duration more than one and a half longer or even twice longer than duration of the other thirdorder (i.e., medium) sequences (Table 2). For instance, the sum of durations of the two sequences PI8Toa2 and Toa2-Toa4 sequences is $2.1 \mathrm{Myr}$ (according to GTS2004), thus close to the duration of Toa6-Toa7 alone. In addition, a thick section of calcareous silts and silty shales with rare ammonites is studied in the subsiding part of the southeastern France Basin, which may represent two sequences rather than one (Graciansky et al., 1993). Interestingly, a well expressed third-order sequence within Thouarsense Zone was recognized only in the Quercy basin (numbered as Toa5 in Bonnet et al., 1992), and thus was not retained in the chart. Also, it was shown that Toa4-Toa5, Toa5-Toa6, Toa6-Toa7 and Toa7-Aa1 sequences are amalgamated in several sections of southeastern France Basin (Graciansky et al., 1998). These observations do not preclude that one or more sequences could be hidden within these condensed sediments.

Only a small part of a possible upper TOAR cycle (or TOAR-7) is recovered in the MS record. The lower minimum of this possible cycle (or upper minimum of TOAR-6) is around the base of Aalensis Zone matching well the Toa7 sequence boundary. This minimum is characterized by a carbonate-rich interval in Sancerre. It is an erosional surface in southeastern France Basin, dated as lower Aalensis Zone (Graciansky et al., 1993). It is well marked by a hardground surface in Quercy basin, also dated as lower Aalensis Zone (upper Mactra Subzone, Graciansky et al., 1998). 